\title{
Changes of total versus extreme precipitation and dry periods until the end of the twenty-first century: statistical assessments for the Mediterranean area
}

\author{
E. Hertig • S. Seubert • A. Paxian • G. Vogt $\cdot$ H. Paeth • \\ J. Jacobeit
}

\begin{abstract}
Changes of total precipitation, extreme precipitation, and dry periods in the Mediterranean area until the end of the twenty-first century have been assessed by means of statistical downscaling. Generalized linear models using predictors describing the large-scale atmospheric circulation as well as thermodynamic conditions have been applied for the projections under A1B and B1 scenario assumptions. The results mostly point to reductions of total and extreme precipitation over the western and central-northern Mediterranean areas in summer and autumn and to increases in winter. In contrast, over the eastern Mediterranean area widespread precipitation increases are assessed in summer and autumn, whereas reductions dominate in winter. In spring, total and extreme precipitation decreases prevail over the whole Mediterranean area. Total and extreme precipitation decreases mostly come along with increases of the maximum dry period length. Vice versa precipitation increases are commonly accompanied by a shortening of the maximum dry period length.
\end{abstract}

\section{Introduction}

In the context of future climate change, questions about changes related to precipitation are of particular interest. In view of societal, economic, and ecological issues it is not

E. Hertig $(\varangle) \cdot$ S. Seubert $\cdot$ J. Jacobeit

Institute of Geography, University of Augsburg,

Universitaetsstr. 10,

86135 Augsburg, Germany

e-mail: elke.hertig@geo.uni-augsburg.de

A. Paxian $\cdot$ G. Vogt $\cdot$ H. Paeth

Institute of Geography and Geology, University of Wuerzburg,

Wuerzburg, Germany only important to know about changes of mean precipitation, but also the modification of the extreme tails of the precipitation distribution is of utmost significance. Coupled atmosphere-ocean general circulation model (AOGCMs) results suggest that future changes in precipitation extremes will likely be greater than changes in mean precipitation (Meehl et al. 2007), with mean precipitation being reduced in some parts of the world while extreme precipitation increases almost everywhere (Kharin and Zwiers 2005). The anticipated changes in mean and extreme precipitation in different regions have been related to dynamic (e.g., large-scale circulation) and thermodynamic processes (e.g., convective instability). Greater increases in extreme precipitation compared to the mean have been explained by the greater thermodynamic effect on the extremes due to increases in water vapor, especially in the subtropics (Emori and Brown 2005; Meehl et al. 2005). Yet at middle and high latitudes the pattern of precipitation intensity changes also shows a clear link to changes of the atmospheric circulation (Meehl et al. 2005). Over most parts of the northern subtropics and midlatitudes precipitation is projected to be concentrated into more intense events, with longer relatively dry periods in between. In this regard, models simulate that in a future warmer climate summer dryness will increase in these areas with associated increased risk of droughts (Rowell and Jones 2006; Wang 2005).

Within the context of regional specifications of global climate change, the Mediterranean area depicts an exceptionally interesting region as being located in the transitional zone between tropical and extratropical circulation dynamics; it has been identified as a "climate change hot-spot", due to the projected increase of the inter-annual precipitation variability, a decrease of total precipitation, and an increase of temperature mainly during the dry season (Giorgi 2006). AOGCMs (e.g., Giorgi and Lionello 2008), 
regional climate models (RCMs; e.g., Gao et al. 2006), as well as statistical downscaling results (e.g., Hertig and Jacobeit 2008) agree on the overall assessment that total precipitation will be reduced in spring, summer, and autumn until the end of the twenty-first century in the Mediterranean area. In winter, the projections point to decreased precipitation over the southern and eastern parts of the Mediterranean area, whereas the western and northern parts might experience precipitation increases. But the amount and the exact spatial extent of these increases are still rather uncertain since they strongly depend on the future evolution of the factors governing rainfall generation, like, e.g., thermodynamic forcing and Mediterranean cyclones which frequently operate on small spatial scales (Jansa et al. 2001) as well as cyclonic pathways being influenced by a general northward shift and intensification of the midlatitude storm track (Lionello and Giorgi 2007).

Regarding precipitation-related extremes, uncertainties are still very high partly due to model deficiencies to represent these rare events correctly. As an overall indication different AOGCM and RCM projections (e.g., Tebaldi et al. 2006; Beniston et al. 2007) point to increases of extreme precipitation in the northern Mediterranean area whereas the southern and eastern Mediterranean regions will mostly be affected by decreases until the end of the twenty-first century. Results of a recent statistical downscaling assessment by Hertig et al. (2011) mainly yield decreases of extreme precipitation over many parts of the Mediterranean area in spring. In summer, increases are assessed around the Tyrrhenian Sea, the Ionian Sea, and the Aegean Sea, whereas decreases are projected for most of the western and northern Mediterranean regions. In autumn, reductions of heavy rainfall occur over many parts of the western and central Mediterranean area, whereas some regions of the eastern Mediterranean area are affected by increases. In winter, distinct increases can be seen for many parts of the Mediterranean area.

Concerning dry periods, a long-term trend of drying was already evident over the Mediterranean area from 1900 to 2008 (Dai 2011), and the risk of these events is likely to increase in the future. Thus, Sillmann and Roeckner (2008) assess significant increases of the consecutive dry day (CDD) index in regions around the Mediterranean Sea, especially along the African coast. This finding is in accordance with a study of Tebaldi et al. (2006) who also find a significant increase in dry days (defined as the annual maximum number of consecutive dry days). Furthermore, Weiß et al. (2007) assess that 100-year droughts will occur more frequently in the future over large parts of the Mediterranean area.

The aim of the present paper is to further investigate the questions on changes of heavy rainfall events, dry periods and the relation of these extremes to total precipitation changes in the Mediterranean area until the end of the twenty-first century. A specific statistical downscaling approach is chosen to pursue these questions in a consistent manner. Generalized linear models (GLMs) are applied as downscaling technique to assess total precipitation as well as different indices of heavy rainfall and dry spells on a fine-scale spatial resolution. In the study region, precipitation-related events are connected to variations of the large-scale circulation as well as to convective activity on smaller spatial scales. To account for this, predictor variables from both groups are included, keeping in mind that the different variables are interdependent. Furthermore, a specific statistical ensemble technique is used for the assessments to account for nonstationarities in the predictors-predictand relationships, yielding a range of possible future realizations of precipitation and precipitation-related indices.

A description of the data used and the methodology applied is given in Section 2. In order to take into account different sources of uncertainties, two different scenarios (A1B and B1), multiple runs for each scenario, and output of two different AOGCMs (ECHAM5 and HadCM3) are included. The results of the assessments for seasonal total precipitation, for extreme precipitation (total amount and its relation to mean precipitation) and for dry periods (expressed as the number of consecutive dry days) are presented in Section 3. This is followed by a discussion and some conclusions in Section 4.

\section{Data and methodology}

\subsection{Data}

\subsubsection{Predictands}

In the present study, seasonal precipitation totals (PREC) as well as different 95th percentile-based indices of extreme precipitation are selected, characterizing the seasonal total amount of heavy rainfall events (R95AM, precipitation total from events exceeding the 95th percentile; Moberg et al. 2006) and its relation to seasonal precipitation totals (R95T, percentage of total precipitation from events exceeding the 95th percentile). The extreme precipitation index R95AM is taken from an analysis described in Hertig et al. (2011), followed by the calculation of R95T from the assessment results of PREC and R95AM $(\mathrm{R} 95 \mathrm{~T}=(\mathrm{R} 95 \mathrm{AM} / \mathrm{PREC}) \times$ 100). To account for the specific characteristics of the Mediterranean rainfall regime (for details, see Hertig et al. 2012), only days with a minimum rainfall amount of $0.1 \mathrm{~mm}$ are included in the calculations of the indices based on the 95th percentile. Furthermore, the number of CDD index is taken to represent dry periods on a seasonal basis. CDD is calculated for each season as the maximum number of consecutive days with a precipitation amount below $1 \mathrm{~mm}$. 
Precipitation data for the Mediterranean land areas are taken from the highly resolved E-OBS gridded dataset (Haylock et al. 2008a, b). This dataset contains daily values of precipitation on a $0.25^{\circ} \times 0.25^{\circ}$ grid for the European land areas. All grid boxes within the area from $27^{\circ}$ to $46.5^{\circ} \mathrm{N}$ and from the North Atlantic Ocean $\left(10^{\circ} \mathrm{W}\right)$ to $40.5^{\circ} \mathrm{E}$ have been considered which feature a characteristic Mediterranean precipitation regime, i.e., showing a summer minimum of precipitation. Further specifications of the Mediterranean rainfall regime, like its spatial variability, are described in Hertig et al. (2012). Precipitation totals and the indices described above are calculated for each grid box with a seasonal resolution for the time period 1950-2006. After excluding grid boxes which contain more than $20 \%$ missing values and more than $80 \%$ zero-rainfall amounts, 2,940 grid boxes are available in spring (March to May), autumn (September to November), and winter (December to February). In the summer season (June to August), 2,387 grid boxes can be used.

\subsubsection{Predictors}

The necessity to take the choice of the predictor variables into careful consideration has been extensively discussed within the context of statistical downscaling (e.g., Wilby and Wigley 2000; see Hertig et al. 2011 in connection with the Mediterranean area). Mediterranean precipitation is generally induced by large-scale advection and/or it is a matter of smaller-scale convective activity. Therefore, various predictors have been chosen to describe the large-scale circulation as well as convective processes. As atmospheric variables describing the large-scale circulation geopotential heights of the 700 and $500 \mathrm{hPa}$ levels are chosen as well as the $u$ (zonal) and the $v$ (meridional) wind components of the $850 \mathrm{hPa}$ level. In order to consider convective processes, specific humidity of the 850 and $700 \mathrm{hPa}$ levels are selected as predictors, as well as the Showalter Index (Showalter 1953) and a proxy for convective inhibition (CIN, calculation adopted from Myoung and Nielsen-Gammon (2010)). Details of the calculation procedure for the convective indices (Showalter Index and CIN) are given in Appendix 1.

The predictor variables in the observational period 1950 2006 are obtained from the National Centers for Environmental Prediction/National Center for Atmospheric Research NCEP/NCAR reanalysis project (Kalnay et al. 1996; Kistler et al. 2001). Geopotential heights of the 700 and $500 \mathrm{hPa}$ levels are taken from the area $20-70^{\circ} \mathrm{N}$ and $40^{\circ} \mathrm{W}-50^{\circ} \mathrm{E}$. The other predictor variables are selected for the area $27.5-52.5^{\circ} \mathrm{N}$ and $12.5^{\circ} \mathrm{W}-42.5^{\circ} \mathrm{E}$ (horizontal resolution of $2.5^{\circ} \times 2.5^{\circ}$ in each case). The limits of the larger area for the geopotential heights incorporate the major dynamical influences on the Mediterranean area, especially the midlatitude westerlies in the upstream area. Tests with different sizes of the predictor domains showed that for the other predictor variables a smaller size, concentrated over the target area itself, works better within the statistical downscaling procedure.

Model output of the ECHAM5/MPI-OM-AOGCM (Roeckner et al. 2003, 2006) and of the UKMO-HadCM3AOGCM (Gordon et al. 2000; Pope et al. 2000) is taken for the model predictors in context of extending the statistical downscaling approach to future projection periods. The forcing uses observed greenhouse gas emissions for 1950 2000 and Special Report on Emission Scenarios (SRES) A1B as well as SRES B1 scenario emissions (Nakicenovic and Swart 2000) from 2001 to 2100. Three ensemblemember simulations for the twentieth century and the A1B and $\mathrm{B} 1$ scenarios are used from the ECHAM5 model as well as one simulation in each case from the HadCM3 model. General data preprocessing includes the fitting of the horizontal resolution of the model output data $\left(\mathrm{T} 63, \sim 1.875^{\circ}\right)$ to those of the observed predictor data $\left(2.5^{\circ} \times 2.5^{\circ}\right)$.

To check whether the GCMs are generally able to reproduce large-scale circulation correctly, the output of the twentieth century control runs are compared with the NCEP/ NCAR reanalysis data in the study period 1950-2006. For the three ECHAM5-A1B model runs (which are predominantly used to present results in detail), it is revealed that there exist some differences like for example lower mean values of geopotential heights in the control runs compared to the reanalysis data mainly over the North Atlantic area between $40^{\circ}$ and $60^{\circ} \mathrm{N}$, and higher mean values over Northern Africa in winter. Regarding the variances of the geopotential height data in the selected spatial domain (20$70^{\circ} \mathrm{N}, 40^{\circ} \mathrm{E}-50^{\circ} \mathrm{W}$ ), no significant differences between control experiments and reanalysis data are evident (Studentdistributed test statistics, $99 \%$ significance level). Nevertheless, remaining deficiencies of the GCMs to capture all of the natural variability correctly have to be taken into account within the discussion of the statistically derived assessments of regional precipitation changes in the Mediterranean area (Section 3).

\subsection{Methodology}

\subsubsection{Principal component analysis}

In a first step s-mode, Varimax-rotated principal component analysis (PCA, e.g., Preisendorfer 1988) is applied to each predictor field to reduce dimensions of the data and to define independent (orthogonal) spatial centers of variation within each dataset. PCAs are carried out for several calibration periods (for details on calibration and verification, see Section 2.2.3) in the observational period from 1950 to 2006. The determination of the number of principal components (PCs) to be extracted follows the approach of Philipp 
et al. (2007). Depending on the particular season, the geopotential height fields are reduced to eight up to $12 \mathrm{PCs}$ with overall explained variances (EVs) between 90 and $96 \%$. The wind components (note the smaller domain of these variables compared to the geopotential height fields) are reduced to eight up to $16 \mathrm{PCs}$, the specific humidity fields to 10 up to $18 \mathrm{PCs}$, and the convective indices to seven up to 15 PCs, all of them with EVs of about $90 \%$. Generally, more PCs are necessary in the summer season to describe the large-scale variation within a predictor field compared to the other seasons.

Subsequently, the time series of the predictands at each individual E-OBS grid box are separately linked to the large-scale atmospheric circulation represented by their corresponding PC time series. The predictor-predictand relationships are then used to assess the response of the small-scale predictand to changes of the large-scale predictors. For this purpose, the reanalysis data in the verification periods as well as the GCM model data of the control runs, the $\mathrm{A} 1 \mathrm{~B}$ and $\mathrm{B} 1$ scenario runs are projected in each case onto the existing PCs of the observational period to obtain new predictor time series.

\subsubsection{Generalized linear models}

GLMs (e.g., McCullagh and Nelder 1989) are used to derive relationships of the various predictands with the large-scale predictors. Maximum likelihood estimation is used to derive a model for the expectation value of a variable at any given time. In case of PREC, the variance function can best be described by a gamma distribution with $V(\mu)=\mu^{2}$, with $\mu$ being the mean for the PDF. The associated canonical link for this distribution is reciprocal $\left(\eta=\mu^{-1}\right)$. The usefulness of the gamma distribution to provide a good fit to the precipitation data and to enable precipitation amounts to be accurately expressed is reported in many studies related to the Mediterranean area, e.g., Ben-Gai et al. (1998) for Israel, Brunetti et al. (2001, 2004) for Italy, and Lana and Burgueño (2000) for Spain.

In the scope of modeling the seasonal number of CDD, a log-linear model is applied. In this case, the variance function used by the GLM is $V(\mu)=\mu$, assuming a Poisson process with the canonical link $\log (\eta=\log \mu)$. In a study by Lana and Burgueño (1998) for Catalonia, the Poisson distribution has also been found to fit well to the extreme dry events being characteristic for the Mediterranean area.

A detailed description of the GLMs for the precipitation total from events above the 95th percentile (R95AM) is given in Hertig et al. (2011). In few words: zero values in the time series of R95AM are disregarded and a GLM is established for the resulting continuous data. In the calibration periods, the information about the occurrence of an extreme event is retrieved from the original time series. So as to get the complete time series in the verification periods and in the model periods, the information about zero values is taken from a separate modeling of the number of events exceeding the 95 th percentile. The variance function of R95AM is described by a gamma distribution with $V$ $(\mu)=\mu^{2}$, and maximum quasi-likelihood models are established with the canonical link $\log (\eta=\log \mu)$.

For the purpose of getting information about the changes of the ratio of total versus extreme precipitation, the percentage of total rainfall from events exceeding the 95th percentile (R95T) is also considered. In order to ensure reliable results from the GLMs, 100 iterations of bootstrapping have been performed for each model. Only predictor variables which have a significant regression coefficient $(t$ test with a significance level of 0.1 ) are included in the models. As a measure of the overall ability of a model, the discrepancy of the fit is examined by the generalized Pearson $X^{2}$ statistic (McCullagh and Nelder 1989). Further diagnostic procedures are applied to examine the residuals by looking at the deviance residual and the Pearson residual (McCullagh and Nelder 1989). Additional measures for the model performance are used within the context of the calibration and verification procedure which is described in the next section.

\subsubsection{Validation}

To judge the overall performance of the statistical downscaling models, the whole study period 1950-2006 is divided into five calibration periods, each comprising 47 years (46 years in winter, because December of the last year has no subsequent January and February values to calculate the winter value). Each of the five verification periods comprises 10 years which are not included in the corresponding calibration periods: 1956-1965, 1966-1975, 1976-1985, 1986-1995, and 1996-2005 (e.g., 1950-1955 and 19662006 are used as calibration period, and 1956-1965 as verification period, etc.). The predictor-predictand relationships are established and evaluated in each calibration period. Subsequently, they are verified in the corresponding independent verification period. The specific validation approach results in statistical model ensembles including multiple models which cover a range of the observed natural variability and allow for the detection of nonstationarities in the circulation-precipitation relationships. Model performance is determined by means of the correlation coefficients between modeled and observed predictands in the calibration as well as in the verification periods. Additionally mean error, bias, and the reduction of variance (RV) are calculated. The $\mathrm{RV}$ "reference" in the present study is the mean of the observations from the verification sample. $\mathrm{RV}=100 \%$ would mean a perfect model, $\mathrm{RV}=0 \%$ implies no improvement compared to the simple use of the sample climatology, and RV $>0 \%$ indicates some improvement by the model results. 
In a first step, the statistical downscaling procedure is separately applied for each predictor type. Subsequently, a joint analysis is conducted with the PCs selected in the single-predictor analyses serving as potential predictors in the multitype-predictor analysis. The model with the best performance for each grid box and each calibration/verification period is selected for future projections. Thus, a multitype predictor assessment in terms of a specific combination of individual predictor variables is used whenever it yields better results than an assessment with a single predictor. Otherwise, the single predictor model is taken. This implies that for a certain grid box, a statistical model ensemble becomes available which incorporates a larger range of the observed natural variability including differing influences from the various predictor types thus providing a particular quantification of uncertainties.

The assessment results are presented as the changes in the future time slice 2070-2099 in relation to the control run period 1961-1990. In the future period, A1B and B1 scenario conditions are considered under the use of multiple ECHAM5 runs (three-member ensemble simulations) as well as one particular HadCM3 run. Additionally, for each grid box, the upper and lower limits of the $95 \%$ bootstrap confidence interval (DiCiccio and Efron 1996) for the assessed changes between the two 30-year periods are calculated. The bootstrap confidence intervals are calculated by taking 1,000 iterations. In addition, the ensemble mean changes for the future period 2070-2099 in relation to the reference period 1961-1990 are tested for significant differences $(95 \%$ level) using the nonparametric $U$ test (Mann and Whitney 1947).

\section{Results}

\subsection{Total precipitation}

The results of the statistical downscaling assessments of the seasonal precipitation totals based on generalized linear models using the information of the large-scale predictors 700 and $500 \mathrm{hPa}$ geopotential heights, $u$ and $v$ wind components of the $850 \mathrm{hPa}$ level, 850 and $700 \mathrm{hPa}$ specific humidity, convective inhibition, and Showalter Index are discussed in this section.

\subsubsection{Model and predictor performance}

Correlation coefficients between statistically modeled and observation-based values of seasonal precipitation totals in the calibration and verification periods generally show the highest values in the winter season with values of about $0.7-$ 0.9 at almost any region in the Mediterranean area. Only some regions show lower values of about 0.5 , mostly located in the eastern lee sides of mountain ranges, for example at the eastern side of the Apennine Mountains of Italy or at the Mediterranean coast of Spain (parts b and c of Fig. 1). Also, RV values are widespread high in the Mediterranean region, ranging from 20 up to $90 \%$ in calibration and verification (parts $d$ and e of Fig. 1). Overall in the winter season, 10,386 statistical models can be established for 2,846 grid boxes implying that per grid box statistical models are available in average for about four out of five calibration/verification periods. Yet from Fig. 1a, it can be seen that the size of the statistical model ensemble per grid box is not equally distributed over the Mediterranean area, but varies from region to region. In theory, a total of 14,700 models would be possible (statistical transfer functions in five calibration/verification periods for 2,940 grid boxes). But for some grid boxes, no model can be successfully derived (94 grid boxes in winter); and for the remaining 2,846 grid boxes, often no model can be established for some of the five calibration/verification periods. Thus, the number of models is reduced to a total of 10,386.

With reference to the Mediterranean area as a whole, the lowest model quality can be found for the summer season. The correlation coefficients in calibration and verification amount to $0.4-0.8$, the RV values lie in the range of 10 up to $85 \%$. The highest values can be found over the centralnorthern Mediterranean area, whereas the lowest values occur over central parts of the Iberian Peninsula, western North Africa, and Turkey. Note that for the eastern Mediterranean area, no assessment is possible due to the completely dry character of this region in summer. Overall, 6,273 downscaling models can be derived for 2,109 grid boxes.

In the transitional seasons spring and autumn, the correlation coefficients amount to $0.5-0.9$ and the RV values to $15-80 \%$. The highest values can be found over the western and northern Mediterranean regions, the lowest values occur over the eastern Mediterranean area. In spring, 8,708 statistical models are established for 2,863 grid boxes, in autumn 8,715 models for 2,806 grid boxes.

Looking at Table 1, which presents the number a specific predictor is selected in the GLMs, reveals that geopotential heights of the $700 \mathrm{hPa}$ level are the most important predictor, indicating that seasonal precipitation is primarily controlled by the large-scale circulation. Seven hundred $\mathrm{hPa}$ geopotential heights are chosen as predictor in 2,116 statistical models $(24.30 \%$ of all models) for spring, in 1,102 models $(17.57 \%)$ for summer, in 2,326 models (26.69 \%) for autumn, and in 1,752 models (16.87\%) for winter. Only in winter, the $850 \mathrm{hPa}$ zonal wind component is selected more frequently in the models $(2,273$ cases or $21.89 \%$ of all winter models), pinpointing to the importance of advection of moist air masses in the context of the cyclonic westerlies being dominant in this season. In this context, $850 \mathrm{hPa}$ specific humidity also plays a major role in 

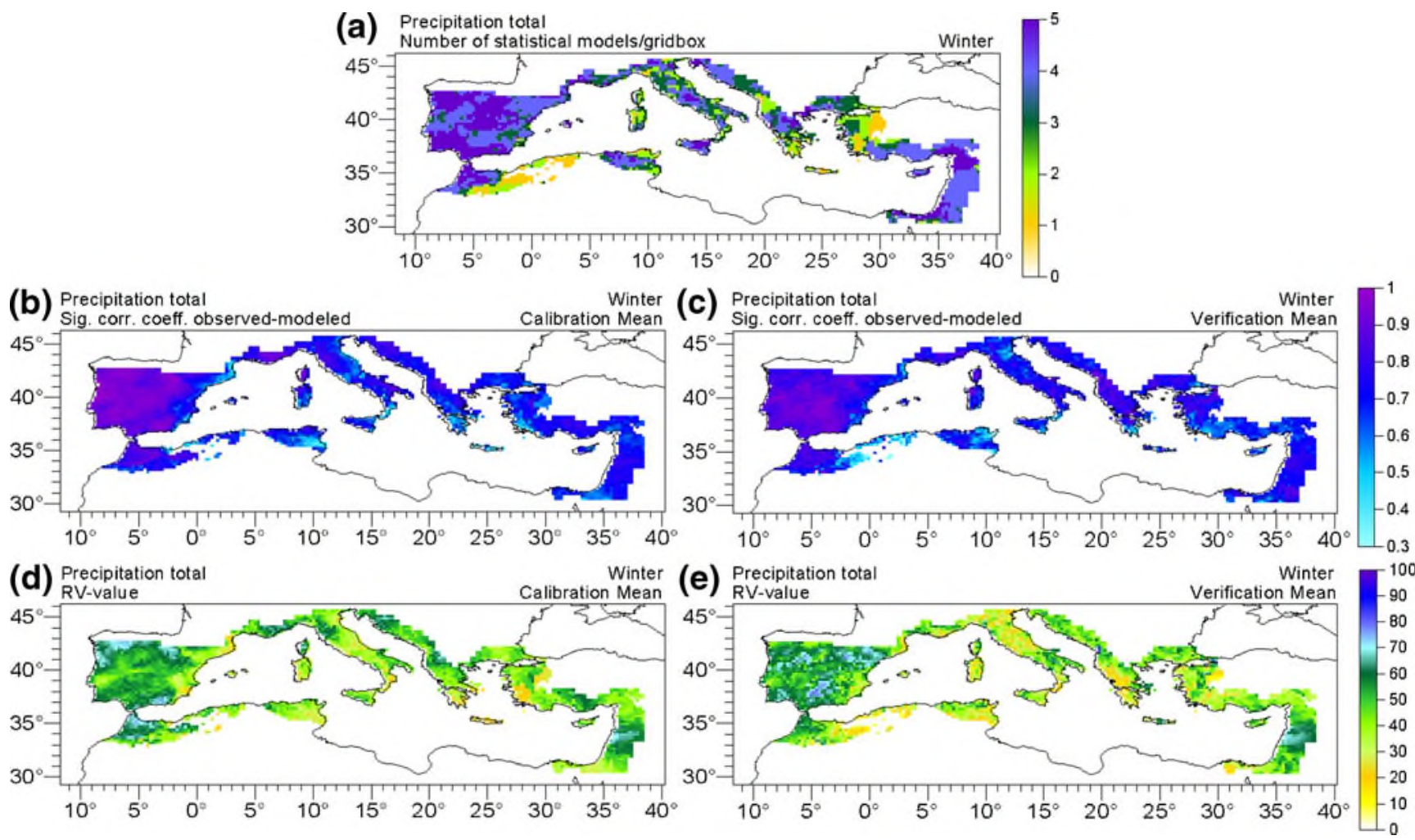

Fig. 1 Statistical model performance for seasonal precipitation totals in winter (December to February). a Size of the statistical model ensemble per grid box (maximum, 5). b Correlation coefficients between modeled and observed precipitation in the calibration period (mean value over the statistical model ensemble). c Correlation

coefficients between modeled and observed precipitation in the verification period (ensemble mean). d Reduction of variance (RV) for the calibration period (ensemble mean). e RV for the verification period (ensemble mean)

the winter season. In contrast to that, during spring and summer, convective inhibition constitutes a prominent predictor, being an indicator for the strength of anticyclonic conditions which build up and are prevailing over the Mediterranean area during the course of these seasons. In the transitional seasons, spring and autumn, the $850 \mathrm{hPa}$ meridional wind component is also vitally important, illustrating the relevance of meridional circulation types for precipitation in these seasons. The Showalter Index represents the least important predictor in all seasons but autumn (selected in about $5 \%$ of all models). In autumn, $700 \mathrm{hPa}$ specific humidity is least important (439 models, $5.04 \%$ ).

\subsubsection{Total precipitation change until the end of the twenty- first century}

Figure 2 illustrates the ensemble mean changes of the seasonal precipitation totals for the future period 2070-2099 in relation to the control run period 1961-1990 both in millimeter (part A) and percentages (part B). The ensemble mean covers the respective statistical model ensembles generated under the use of the three ECHAM5/MPI-OM runs under SRES A1B scenario assumptions. In addition, the significance of the changes ( $95 \%$ level, $U$ test, part C) and the

upper and lower limits of the $95 \%$ bootstrap confidence intervals (part D) are shown. It becomes evident that in spring, precipitation decreases until the end of the twenty-first century dominate over the Mediterranean area. Decreases are strongest and significant over parts of the Iberian Peninsula, western North Africa, the eastern coast of the Ionian Sea, and the southeastern coast of Turkey with values up to $-60 \mathrm{~mm}$. In the summer season, total precipitation changes are split into mainly negative ones over the western and central-northern Mediterranean area of up to $-70 \mathrm{~mm}$, and some precipitation increases over the central and north-eastern Mediterranean with values up to $40 \mathrm{~mm}$. In autumn, strong and significant precipitation reductions with a magnitude of $-100 \mathrm{~mm}$ are assessed for the southern parts of the Iberian Peninsula and around the Adriatic Sea. In contrast, precipitation increases become visible over the northeastern and eastern Mediterranean area. In winter, widespread increases of total precipitation are projected from the statistical downscaling approach. Increases reach values up to $200 \mathrm{~mm}$, but they are mostly not significant according to the $U$ test due to the generally higher precipitation amounts in this season. In contrast to that, significant precipitation reductions up to $-80 \mathrm{~mm}$ are assessed over the eastern Mediterranean area in winter. In 
Table 1 Frequency of the predictors selected as independent variables within the statistical downscaling models for seasonal precipitation totals (PRECtotal)

\begin{tabular}{|c|c|c|}
\hline Predictor & No. of models & Percentage \\
\hline PRECtotal/spring & 8,708 & $100 \%$ \\
\hline $700 \mathrm{hPa}$ geopotential heights & 2,116 & 24.30 \\
\hline Convective inhibition & 1,247 & 14.32 \\
\hline $850 \mathrm{hPa}$ meridional wind & 1,217 & 13.98 \\
\hline $850 \mathrm{hPa}$ zonal wind & 1,143 & 13.13 \\
\hline $500 \mathrm{hPa}$ geopotential heights & 977 & 11.22 \\
\hline $700 \mathrm{hPa}$ specific humidity & 642 & 7.37 \\
\hline Multitype predictor combination & 593 & 6.81 \\
\hline $850 \mathrm{hPa}$-specific humidity & 505 & 5.80 \\
\hline Showalter Index & 268 & 3.07 \\
\hline PRECtotal/summer & 6,273 & 100 \\
\hline $700 \mathrm{hPa}$ geopotential heights & 1,102 & 17.57 \\
\hline $500 \mathrm{hPa}$ geopotential heights & 1,006 & 16.04 \\
\hline Convective inhibition & 931 & 14.84 \\
\hline $850 \mathrm{hPa}$ zonal wind & 899 & 14.33 \\
\hline $850 \mathrm{hPa}$-specific humidity & 754 & 12.02 \\
\hline $700 \mathrm{hPa}$-specific humidity & 449 & 7.16 \\
\hline Multi-type predictor combination & 390 & 6.22 \\
\hline $850 \mathrm{hPa}$-meridional wind & 388 & 6.18 \\
\hline Showalter Index & 354 & 5.64 \\
\hline PRECtotal/autumn & 8,715 & 100 \\
\hline $700 \mathrm{hPa}$ geopotential heights & 2,326 & 26.69 \\
\hline $850 \mathrm{hPa}$ meridional wind & 1,293 & 14.84 \\
\hline $850 \mathrm{hPa}$ zonal wind & 1,237 & 14.18 \\
\hline $500 \mathrm{hPa}$ geopotential heights & 839 & 9.63 \\
\hline 850 hPa-specific humidity & 777 & 8.92 \\
\hline Showalter Index & 660 & 7.57 \\
\hline Multitype predictor combination & 594 & 6.82 \\
\hline Convective inhibition & 550 & 6.31 \\
\hline $700 \mathrm{hPa}$-specific humidity & 439 & 5.04 \\
\hline PRECtotal/winter & 10,386 & 100 \\
\hline $850 \mathrm{hPa}$ zonal wind & 2,273 & 21.89 \\
\hline $700 \mathrm{hPa}$ geopotential heights & 1,752 & 16.87 \\
\hline $850 \mathrm{hPa}$ specific humidity & 1,286 & 12.38 \\
\hline $500 \mathrm{hPa}$ geopotential heights & 1,188 & 11.44 \\
\hline Convective inhibition & 1,091 & 10.50 \\
\hline $850 \mathrm{hPa}$ meridional wind & 999 & 9.62 \\
\hline $700 \mathrm{hPa}$ specific humidity & 892 & 8.58 \\
\hline Showalter Index & 521 & 5.02 \\
\hline Multitype predictor combination & 384 & 3.70 \\
\hline
\end{tabular}

The total number of models consists of the number of grid boxes times the number of calibration/verification periods for which a downscaling model can be established. A multitype predictor assessment in terms of a specific combination of individual predictor variables is used whenever it yields better results than an assessment with a single predictor. From top to bottom: results for spring, summer, autumn, and winter summary for the Mediterranean area as a whole, the statistical assessments indicate predominating precipitation decreases in spring, summer, and autumn; whereas in winter, widespread increases are projected until the end of the twenty-first century. However, the eastern Mediterranean area holds a special position in this context, showing rather precipitation increases in summer and autumn in contrast to precipitation decreases in the winter season.

The application of ECHAM5 model output under B1 scenario assumptions yields very similar results to those obtained from ECHAM5-A1B conditions. In contrast, the use of HadCM3 model predictor output for the statistical downscaling leads to partially differing results. The main differences refer to small increases up to about $30 \mathrm{~mm}$ over the northwestern Iberian Peninsula in spring when using HadCM3 data instead of decreases as they are assessed with ECHAM5 data. In autumn, more pronounced precipitation decreases arise from HadCM3 over the western and centralnorthern Mediterranean area of up to $-100 \mathrm{~mm}$ (B1 scenario) and $-140 \mathrm{~mm}$ (A1B scenario), respectively. In winter, the area of precipitation increases is confined to the Iberian Peninsula, southern France, and northern Italy in the downscaling results applying HadCM3 output under A1B scenario assumptions. For the HadCM3-B1 scenario, precipitation increases in winter show a similar spatial pattern as seen from the application of ECHAM5 model data, albeit with generally lower values.

\subsection{Extreme precipitation}

This section deals with the statistical downscaling results of R95AM (precipitation total from events exceeding the 95th percentile) as well as of $\mathrm{R} 95 \mathrm{~T}$ (percentage of total precipitation from events exceeding the 95th percentile). At first model and predictor performance for R95AM is given, followed by the presentation of the ensemble mean changes of R95AM and R95T for the projection period 2070-2099 in relation to the control run period 1961-1990.

\subsubsection{Model and predictor performance}

Model and predictor performance for R95T cannot be specified separately since this index is calculated from the assessment results of seasonal precipitation totals (Section 3.1) and R95AM. An analysis of the model performance within the context of the statistical assessments of R95AM reveals that 6,265 downscaling models can be established for 2,611 grid boxes in spring (using five calibration/verification periods). In the summer season, 5,065 statistical models are successfully derived for 2,150 grid boxes; in autumn, 6,373 models are available for 2,605 grid boxes; and in winter, 7,566 models for 2,618 grid boxes. The ensemble mean correlation coefficients between statistically modeled 

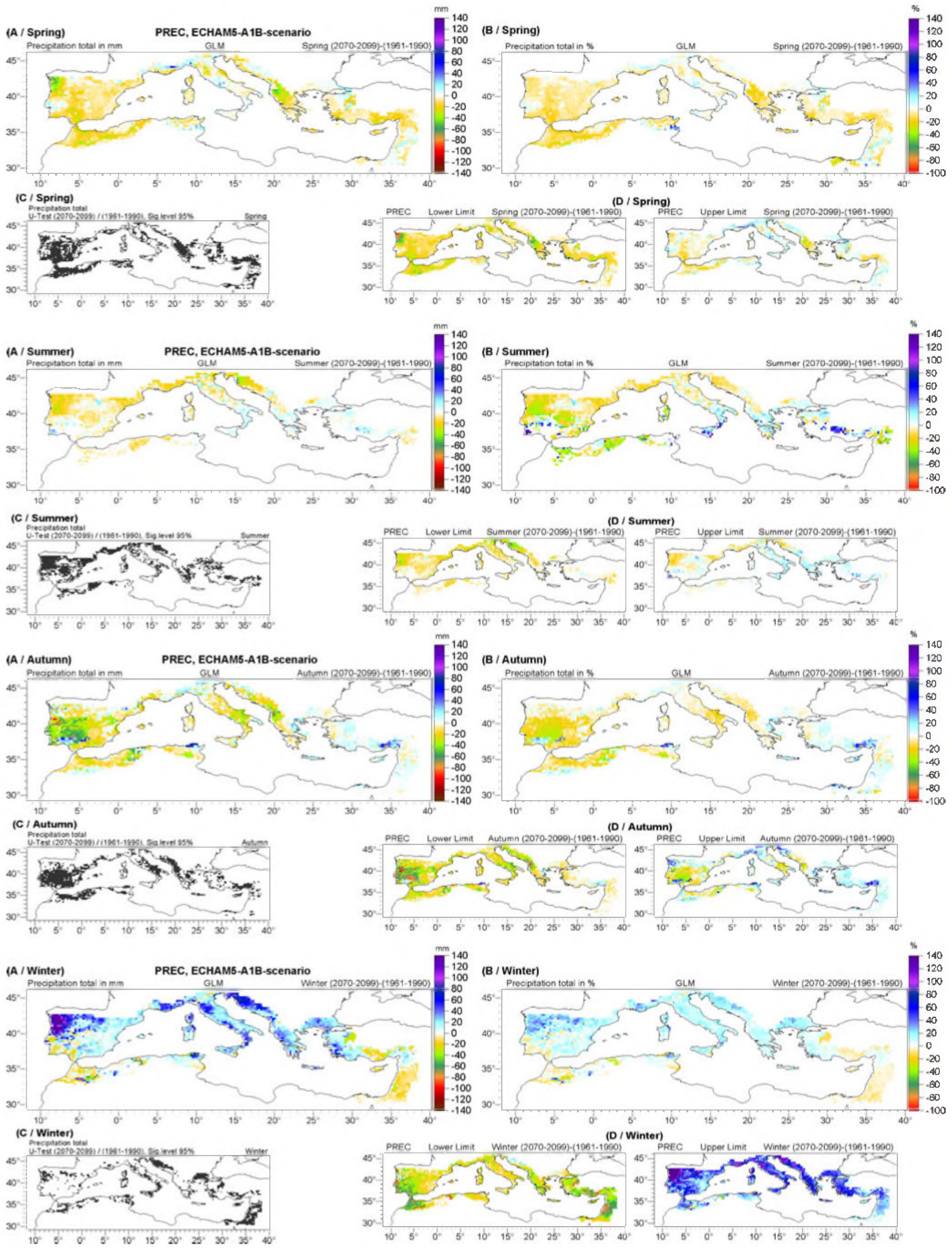
Fig. 2 Ensemble mean changes of seasonal precipitation totals for the future period 2070-2099 in relation to the control run period 19611990 in millimeter (part A) and percentages in relation to the mean of the period 1961-1990 (part B). In addition, the significance of the changes (part C, black signature, significant at the $95 \%$ level, $U$ test) and the upper and lower limits of the $95 \%$ bootstrap confidence intervals (part D) are shown. Results are based on statistical downscaling assessments using generalized linear models as downscaling technique and predictors from three ECHAM5/MPI-OM runs under SRES A1B scenario assumptions. From top to bottom: spring, summer, autumn, winter

and observation-based values of R95AM in the calibration periods range between about 0.4 and 0.8 , the RV takes values up to $90 \%$. In the verification periods, the correlation coefficients amount to $0.3-0.7$ and $\mathrm{RV}$ values are up to about $60 \%$.

Table 2 gives the information on how often a specific predictor is selected in the downscaling models of R95AM in terms of absolute numbers and in relation to the total number of models per season. It can be seen that in spring, the geopotential heights of the $700 \mathrm{hPa}$ level are most frequently selected in the downscaling models for R95AM, followed by the predictors specific humidity of the $700 \mathrm{hPa}$ level and meridional wind component of the $850 \mathrm{hPa}$ level. In the summer season, the most important predictors are $700 \mathrm{hPa}$ geopotential heights, $850 \mathrm{hPa}$ specific humidity, and $500 \mathrm{hPa}$ geopotential heights; whereas in autumn, the $850 \mathrm{hPa}$ meridional wind component is on top of the list, followed by $700 \mathrm{hPa}$ geopotential heights and $850 \mathrm{hPa}$ specific humidity. In winter, specific humidity of the $850 \mathrm{hPa}$ level is most frequently selected, but also $700 \mathrm{hPa}$ geopotential heights as well as the $850 \mathrm{hPa}$ zonal wind component play an important role.

\subsubsection{Extreme precipitation change until the end of the twenty-first century}

Figure 3 shows the statistically assessed changes of R95AM (left side) and of R95T (right side) and the significance of the changes for the period 2070-2099 in relation to the period 1961-1990 under the use of SRES A1B-ECHAM5/MPI-OM model output. It becomes apparent that until the end of the twenty-first century, widespread decreases of the seasonal extreme precipitation total result for the spring season (Fig. 3a, left side). The reductions are strongest and significant ( $U$ test, $95 \%$ level) over the northwestern Iberian Peninsula, northwestern Africa, parts of Greece and Albania, as well as over southeastern Turkey. But since total precipitation is projected to decrease as well in these areas in spring (see Fig. 2), the percentages of extreme precipitation in relation to the total precipitation amounts are only slightly reduced or even show small increases (Fig. 3a, right side).
Table 2 Frequency of the predictors selected as independent variables within the statistical downscaling models for the precipitation total from events exceeding the 95th percentile of daily precipitation (R95AM)

\begin{tabular}{|c|c|c|}
\hline Predictor & No. of models & Percentage \\
\hline R95AM/spring & 6,265 & $100 \%$ \\
\hline $700 \mathrm{hPa}$ geopotential heights & 897 & 14.32 \\
\hline $700 \mathrm{hPa}$ specific humidity & 762 & 12.16 \\
\hline $850 \mathrm{hPa}$ meridional wind & 727 & 11.60 \\
\hline $850 \mathrm{hPa}$ specific humidity & 720 & 11.49 \\
\hline $850 \mathrm{hPa}$ zonal wind & 699 & 11.16 \\
\hline $500 \mathrm{hPa}$ geopotential heights & 633 & 10.10 \\
\hline Showalter Index & 632 & 10.09 \\
\hline Multitype predictor combination & 612 & 9.77 \\
\hline Convective inhibition & 583 & 9.31 \\
\hline R95AM/summer & 5,065 & $100 \%$ \\
\hline $700 \mathrm{hPa}$ geopotential heights & 658 & 12.99 \\
\hline $850 \mathrm{hPa}$ specific humidity & 657 & 12.98 \\
\hline $500 \mathrm{hPa}$ geopotential heights & 635 & 12.54 \\
\hline $850 \mathrm{hPa}$ zonal wind & 572 & 11.29 \\
\hline Multitype predictor combination & 568 & 11.21 \\
\hline Convective inhibition & 538 & 10.62 \\
\hline $700 \mathrm{hPa}$-specific humidity & 496 & 9.79 \\
\hline Showalter Index & 476 & 9.40 \\
\hline $850 \mathrm{hPa}$ meridional wind & 465 & 9.18 \\
\hline R95AM/Autumn & 6,373 & $100 \%$ \\
\hline $850 \mathrm{hPa}$ meridional wind & 837 & 13.13 \\
\hline $700 \mathrm{hPa}$ geopotential heights & 812 & 12.74 \\
\hline $850 \mathrm{hPa}$-specific humidity & 768 & 12.05 \\
\hline $850 \mathrm{hPa}$ zonal wind & 752 & 11.80 \\
\hline $700 \mathrm{hPa}$ specific humidity & 712 & 11.17 \\
\hline Showalter Index & 649 & 10.19 \\
\hline Multi-type predictor combination & 625 & 9.81 \\
\hline $500 \mathrm{hPa}$ geopotential heights & 612 & 9.60 \\
\hline Convective inhibition & 606 & 9.51 \\
\hline R95AM/winter & 7,566 & $100 \%$ \\
\hline $850 \mathrm{hPa}$ specific humidity & 1,146 & 15.16 \\
\hline $700 \mathrm{hPa}$ geopotential heights & 1,049 & 13.86 \\
\hline $850 \mathrm{hPa}$ zonal wind & 906 & 11.97 \\
\hline Convective inhibition & 874 & 11.55 \\
\hline Showalter Index & 788 & 10.42 \\
\hline $700 \mathrm{hPa}$ specific humidity & 775 & 10.24 \\
\hline $850 \mathrm{hPa}$ meridional wind & 747 & 9.87 \\
\hline $500 \mathrm{hPa}$ geopotential heights & 725 & 9.58 \\
\hline Multitype predictor combination & 556 & 7.35 \\
\hline
\end{tabular}

The total number of models consists of the number of grid boxes times the number of calibration/verification periods for which a downscaling model can be established. A multitype predictor assessment in terms of a specific combination of individual predictor variables is used whenever it yields better results than an assessment with a single predictor. From top to bottom: results for spring, summer, autumn, and winter 

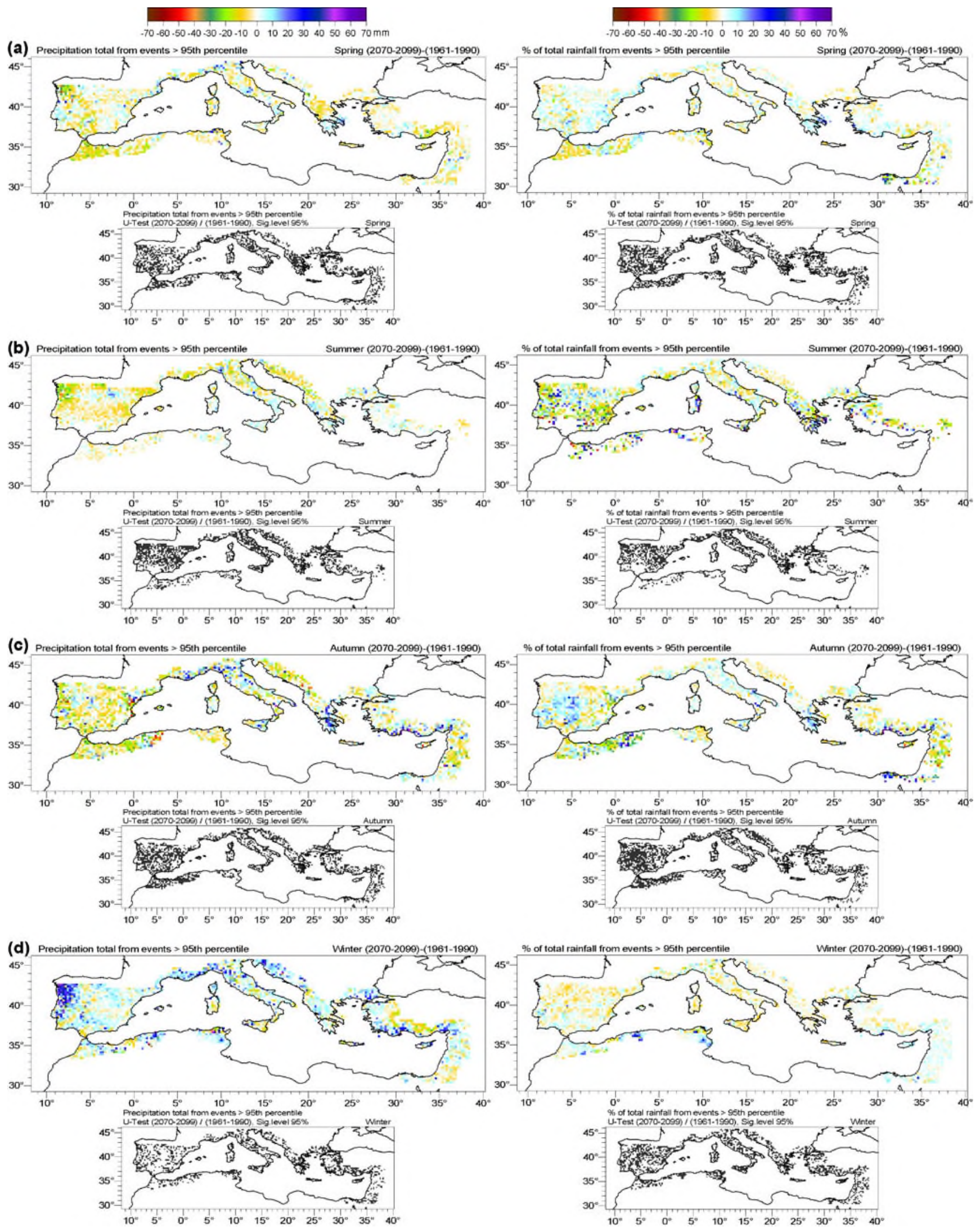

In the summer season, mainly reductions of R95AM of up to about $-40 \mathrm{~mm}$ become visible over the western and

northern Mediterranean area, whereas increases of up to about $30 \mathrm{~mm}$ arise around the Tyrrhenian Sea, the Ionian 
Fig. 3 Ensemble mean changes of R95AM (precipitation total from events exceeding the 95th percentile, left side) and of R95T (percentage of total precipitation from events exceeding the 95th percentile, right side) for the future period 2070-2099 in relation to the control run period 1961-1990 under SRES A1B scenario assumptions. In addition, the significance of the changes (black signature significant at the $95 \%$ level, $U$ test) is shown. Results are based on statistical downscaling assessments using generalized linear models as downscaling technique and predictors from three ECHAM5/MPI-OM runs. From top to bottom: spring, summer, autumn, winter

Sea, and the Aegean Sea (Fig. 3b, left side). The overall spatial pattern of change of R95AM has large similarities with the changes assessed for total precipitation (see Fig. 2), but in terms of absolute amounts the changes are not uniform, reflected in the (partially considerable) changes of R95T (Fig. 3b, right side).

Figure $3 \mathrm{c}$ (left side) illustrates the assessed changes of R95AM in autumn. A decrease of the seasonal extreme precipitation amount until the end of the twenty-first century appears for example over the eastern coast of the Adriatic Sea and some eastern Mediterranean areas as well as over many regions of the western Mediterranean area with the strongest decline over the eastern Mediterranean coast of Spain and parts of Mediterranean Algeria. With the exception of the central Iberian Peninsula, the decreases of extreme precipitation are accompanied by a decrease of R95T, since extreme precipitation is reduced stronger than total precipitation (Fig. 3c, right side). Over the central Iberian Peninsula, however, R95T increases due to the assessed strong decreases of total precipitation. In contrast, over the northern coast of the Ligurian Sea, Greece, and the southern coast of Turkey increases of R95AM and of R95T are assessed in autumn, coming along with mostly increases of total precipitation as well.

In winter, distinct increases of R95AM (Fig. 3d, left side) and of total precipitation (see Fig. 2) dominate the pattern of change. In this context, extreme and total precipitation amounts largely increase with proportional rates resulting in only small changes of R95T (Fig. 3d, right side).

\subsection{Dry periods}

The statistical downscaling results related to dry periods as given by assessments of the number of CDD per season are presented in this section. First, model and predictor performance are discussed followed by the presentation of the projected changes of CDD until the end of the twenty-first century.

\subsubsection{Model and predictor performance}

Looking at the correlation coefficients and the RV values between the statistically modeled and the observation-based time series of CDD in the calibration and the verification periods reveals a quite similar overall model performance in all seasons but winter. In spring, summer, and autumn, the correlation coefficients amount to $0.5-0.9$ and RV takes values of 20 up to $80 \%$, depending on the region considered. In spring, 9,057 statistical models can be established for 2,815 grid boxes; in the summer season, 7,938 models for 2,559 grid boxes; and in autumn, 9,968 models for 2,855 grid boxes, implying that in average at least three statistical models are available for each grid box (out of a maximum of five, arising from the use of five calibration/verification periods). Figure 4 illustrates that in winter, the overall model performance is even higher with correlation coefficients of $0.6-0.9$ and $\mathrm{RV}$ values of $60-80 \%$ in many parts of the Mediterranean area. In this season, 10,419 GLMs can be derived for 2,815 grid boxes.

Regarding the performance of the different predictors, Table 3 reveals that the GLMs give a clear preference to the selection of the geopotential heights of the $700 \mathrm{hPa}$ level as independent variables. Thus, $700 \mathrm{hPa}$ geopotential heights are chosen in about 16-18\% of all downscaling models. This is followed by the still very frequent selection of the $850 \mathrm{hPa}$ zonal wind component in $12-14 \%$ of all GLMs. The only exception from this ranking occurs in summer. In this season, $850 \mathrm{hPa}$ specific humidity, $700 \mathrm{hPa}$ geopotential heights, and $850 \mathrm{hPa}$ zonal wind components are of equal importance, each being incorporated in $12-13 \%$ of all models. In summer as well as in spring and autumn, convective inhibition also represents an important predictor, being selected in about $11-12 \%$ of the downscaling models. In summary, the large-scale atmospheric circulation is of primary importance for the occurrence of local dry periods, e.g., by stable and persisting high-pressure conditions which inhibit the advection of moist air into the target areas and confine the level of convective activity. In summer, the amount of atmospheric humidity is an additionally influencing factor, operating as a trigger for local convective events.

\subsubsection{Dry periods change until the end of the twenty-first century}

Figure 5 illustrates the ensemble mean changes of the maximum number of consecutive dry days of each season for the future period 2070-2099 in relation to the control run period 1961-1990 under SRES A1B scenario assumptions using ECHAM5/MPI-OM model output. Additionally, the significance of the changes ( $95 \%$ level, $U$ test) and the upper and lower limits of the $95 \%$ bootstrap confidence intervals are presented. In spring, the maximum number of consecutive dry days shows increases mainly over the southern and eastern parts of the Mediterranean area with a maximum extension of the dry period length of 14 days over parts of Tunisia. In contrast, the northern Mediterranean regions 

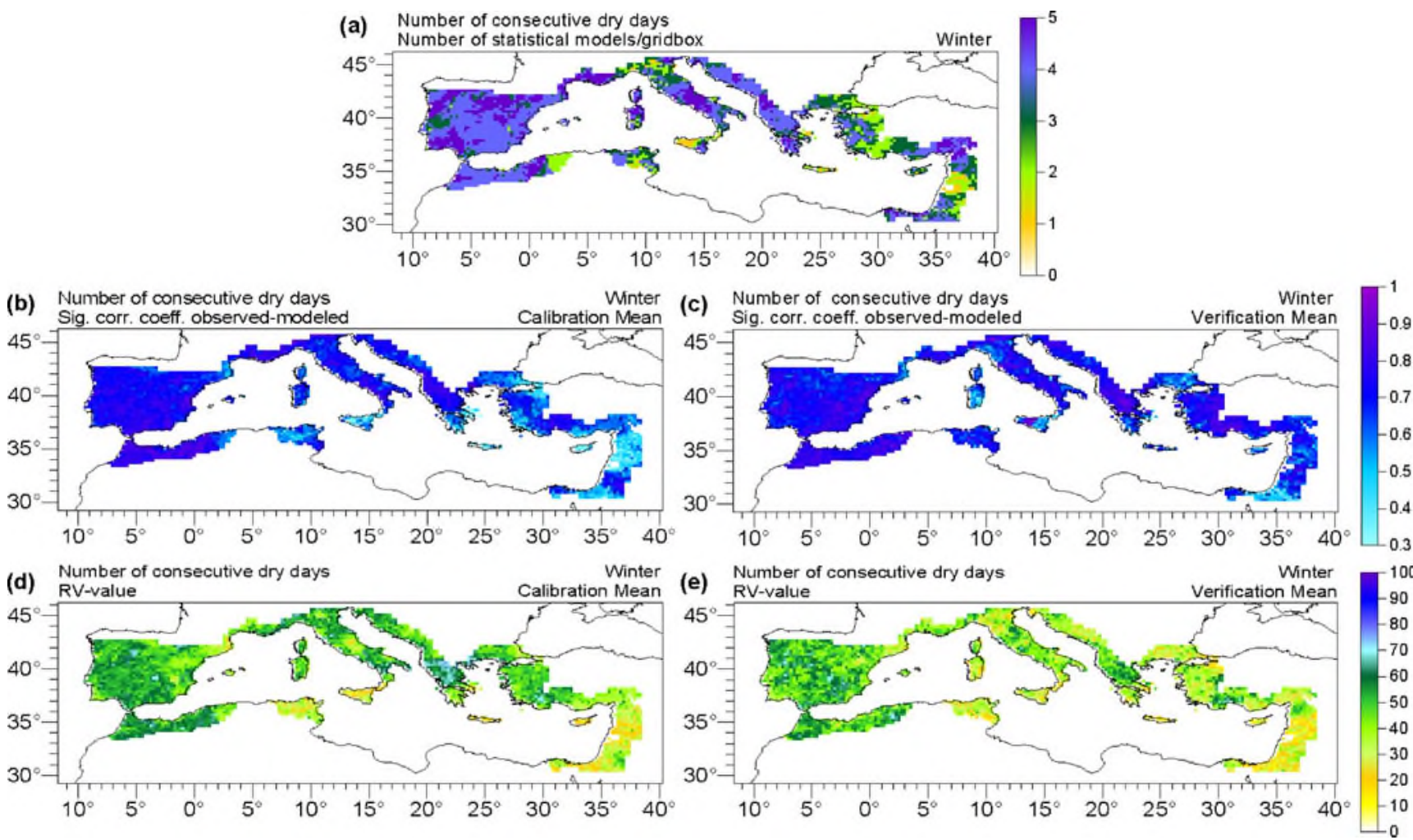

Fig. 4 Statistical model performance for the number of consecutive dry days (CDD) in winter (December to February). a Size of the statistical model ensemble per grid box (maximum, 5). b Correlation coefficients between modeled and observed CDD in the calibration

period (mean value over the statistical model ensemble). c Correlation coefficients between modeled and observed CDD in the verification period (ensemble mean). d Reduction of variance (RV) for the

like, e.g., the western and northern Iberian Peninsula and Italy indicate decreases of the seasonal CDD with a shortening of up to 6 days (Fig. 5a).

In summer, strong and significant modifications of CDD become visible over many parts of the Mediterranean area. Thus, the southeastern parts of the Iberian Peninsula and the western parts of Mediterranean North Africa are affected by a prolongation of the maximum dry period length of up to about 2 weeks, whereas around the Ionian Sea and the Aegean Sea CDD is reduced of up to about 2 weeks (Fig. 5b). The described changes are significant according to the $U$ test (Fig. 5b, lower figure), and the sign of change remains the same within the limits of the $95 \%$ bootstrap confidence interval (Fig. 5b, right figures).

The overall change pattern of CDD in autumn is characterized by extensions of the maximum dry period length over the western Mediterranean area with values of up to 10 days over parts of Algeria and a shortening of CDD over the eastern Mediterranean area, especially over Israel with values of up to -11 days (Fig. $5 \mathrm{c}$ ). In the winter season, small and mostly nonsignificant increases of CDD are assessed over the whole Mediterranean area with the exception of the western parts where some decreases are indicated (Fig. 5d).
Using the weaker B1 emission scenario yields very similar results to those obtained with the A1B scenario. The spatial pattern of change remains unchanged. Differences only exist in the absolute amount of change, with generally less pronounced changes in the $\mathrm{B} 1$ scenario case. Thus, for example, in summer, the extension of CDD over the western Mediterranean area is $2-4$ days less compared to the A1B scenario; and in autumn, the shortening of CDD amounts up to only -8 days over the eastern Mediterranean area. Only small differences also arise when using HadCM3 model output instead of the ECHAM5 ensemble members. One particular difference for HadCM3 predictors can be seen in all seasons over the western Mediterranean region with a stronger shortening of CDD and/or spatially extended areas being affected by this change.

\subsection{Change of total versus extreme precipitation and dry periods}

In this section, a synopsis of the statistical downscaling results of the seasonal precipitation totals, the seasonal total amount of heavy rainfall events (R95AM, precipitation total from events exceeding the 95th percentile), and the seasonal maximum dry period length (CDD) is presented. In this 
Table 3 Frequency of the predictors selected as independent variables within the statistical downscaling models for the number of CDD

\begin{tabular}{|c|c|c|}
\hline Predictor & No. of models & Percentage \\
\hline $\mathrm{CDD} /$ spring & 9,057 & $100 \%$ \\
\hline $700 \mathrm{hPa}$ geopotential heights & 1,536 & 16.96 \\
\hline Multitype predictor combination & 1,487 & 16.42 \\
\hline $850 \mathrm{hPa}$ zonal wind & 1,104 & 12.19 \\
\hline Convective inhibition & 1,063 & 11.74 \\
\hline $850 \mathrm{hPa}$ specific humidity & 1,047 & 11.56 \\
\hline $850 \mathrm{hPa}$ meridional wind & 892 & 9.85 \\
\hline $700 \mathrm{hPa}$ specific humidity & 868 & 9.58 \\
\hline $500 \mathrm{hPa}$ geopotential heights & 606 & 6.69 \\
\hline Showalter Index & 454 & 5.01 \\
\hline $\mathrm{CDD} /$ summer & 7,938 & 100 \\
\hline Multitype predictor combination & 1,034 & 13.03 \\
\hline $850 \mathrm{hPa}$ specific humidity & 1,027 & 12.94 \\
\hline $700 \mathrm{hPa}$ geopotential heights & 1,022 & 12.87 \\
\hline $850 \mathrm{hPa}$ zonal wind & 975 & 12.28 \\
\hline Convective inhibition & 924 & 11.64 \\
\hline Showalter Index & 761 & 9.59 \\
\hline $850 \mathrm{hPa}$ meridional wind & 756 & 9.52 \\
\hline $500 \mathrm{hPa}$ geopotential heights & 753 & 9.49 \\
\hline $700 \mathrm{hPa}$ specific humidity & 686 & 8.64 \\
\hline CDD/autumn & 9,968 & 100 \\
\hline $700 \mathrm{hPa}$ geopotential heights & 1,587 & 15.92 \\
\hline Multitype predictor combination & 1,324 & 13.27 \\
\hline $850 \mathrm{hPa}$ zonal wind & 1,177 & 11.81 \\
\hline $700 \mathrm{hPa}$ specific humidity & 1,164 & 11.68 \\
\hline Convective inhibition & 1,096 & 11.00 \\
\hline $850 \mathrm{hPa}$ specific humidity & 1,056 & 10.59 \\
\hline Showalter Index & 871 & 8.74 \\
\hline $500 \mathrm{hPa}$ geopotential heights & 870 & 8.73 \\
\hline $850 \mathrm{hPa}$ meridional wind & 823 & 8.26 \\
\hline $\mathrm{CDD} /$ winter & 10,419 & 100 \\
\hline $700 \mathrm{hPa}$ geopotential heights & 1,908 & 18.31 \\
\hline $850 \mathrm{hPa}$ zonal wind & 1,474 & 14.15 \\
\hline $850 \mathrm{hPa}$ meridional wind & 1,438 & 13.80 \\
\hline $850 \mathrm{hPa}$ specific humidity & 1,273 & 12.22 \\
\hline $500 \mathrm{hPa}$ geopotential heights & 1,223 & 11.74 \\
\hline Convective inhibition & 1,099 & 10.55 \\
\hline Multitype predictor combination & 732 & 7.02 \\
\hline 700 hPa-specific humidity & 675 & 6.48 \\
\hline Showalter Index & 597 & 5.73 \\
\hline
\end{tabular}

The total number of models consists of the number of grid boxes times the number of calibration/verification periods for which a downscaling model can be established. A multi-type predictor assessment in terms of a specific combination of individual predictor variables is used whenever it yields better results than an assessment with a single predictor. From top to bottom: results for spring, summer, autumn, and winter

context, the sign of change between the periods 2070-2099 and 1961-1990 of total precipitation and extreme precipitation, and of total precipitation and dry periods, respectively, is shown in Fig. 6. In addition, Table 4 gives information on the number and percentage of grid boxes with a specific combination of total precipitation, extreme precipitation, and dry periods change. In the spring season, widespread reductions of total precipitation are assessed, mainly accompanied by reductions of extreme precipitation as well (yellow signature in Fig. 6a, left side) and by extensions of the dry period length (red signature in Fig. 6a, right side). The changes can be seen in context of a shift of the whole precipitation distribution towards lower values accompanied by a prolongation of the maximum dry period length representing the predominant mode of change being assessed for 899 grid boxes ( $35.6 \%$ of all grid boxes, see Table 4 ). On the other hand, there are also some regions, like, e.g., the central and northern parts of the Iberian Peninsula, where all of the three parameters show reductions (yellow signature in both parts of Fig. 6a, 384 grid boxes, $15.2 \%$ of all grid boxes). In this case, the total and extreme precipitation reductions do not go along with longer dry periods, but other mechanisms operate like, e.g., rainfall events with generally less rainfall amounts interspersed with shorter intervals of dry days.

In summer (Fig. 6b) and in autumn (Fig. 6c), it is once more projected for widespread areas of the western and northern Mediterranean regions that total and extreme precipitation amounts will be reduced, coming along with a prolongation of dry periods. This major mode of change can be seen in summer at 547 grid boxes $(29.7 \%)$ and in autumn at 592 grid boxes (23.6\%, Table 4$)$. On the other hand, over parts of the central and eastern Mediterranean area total precipitation is assessed to increase in summer and autumn, mostly accompanied by an increase of extreme precipitation (dark blue signature in the left figures) and by a shortening of the maximum dry period length (light blue signature in the right figures). These changes occur in about $13 \%$ of all grid boxes (Table 4) and can be integrated into the idea of a general shift of the precipitation distribution towards higher values.

In winter, many parts of the Mediterranean area show increases of total precipitation in association with increases in heavy precipitation (dark blue signature in Fig. 6d, left side). Over the Iberian Peninsula, the precipitation changes are accompanied by reductions in the number of consecutive dry days (light blue signature in Fig. 6d, right side); but in the central-northern and northeastern regions, the maximum dry period length increases (dark blue signature in Fig. 6d, right side), implying that generally more intense rainfall events go along with longer dry periods. Table 4 reveals that the latter occurs for 910 grid boxes, being the predominant mode of change in winter (35.5\%). Additionally, it can be seen that the eastern Mediterranean area takes an exceptional position in winter, exhibiting reductions of total precipitation and a widespread increase of extreme precipitation and of the maximum dry period length. This corresponds 
(a) CDD Spring, ECHAM5-A1B-scenario

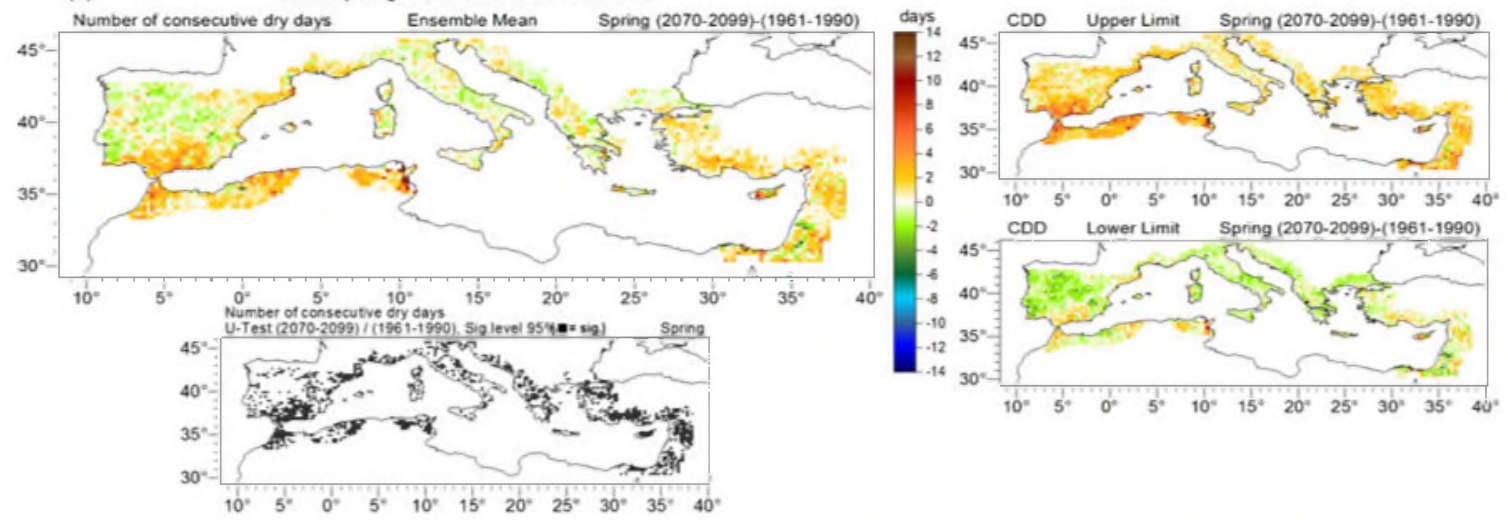

(b) CDD Summer, ECHAM5-A1B-scenario

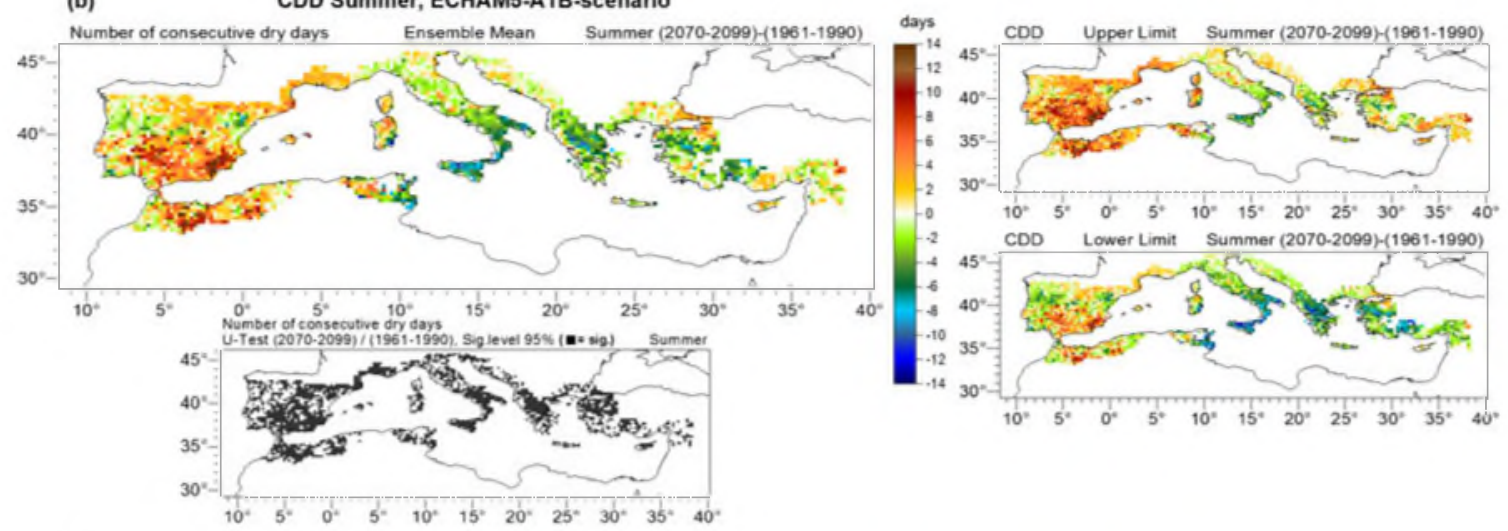

(c)

CDD Autumn, ECHAM5-A1B-scenario

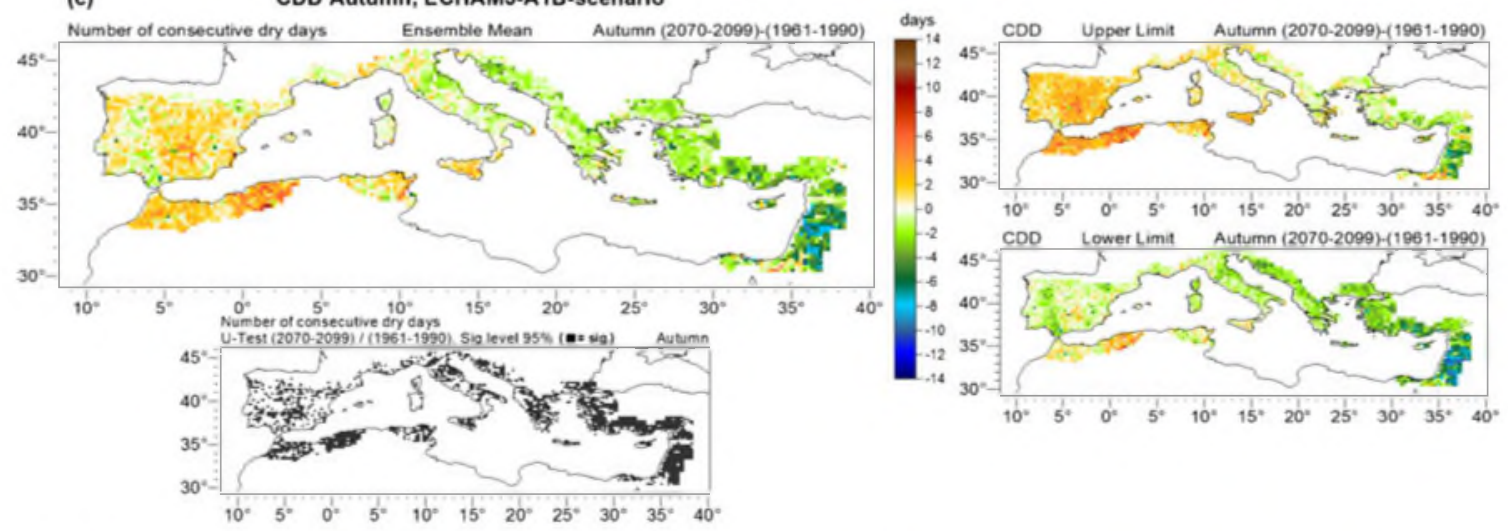

(d) CDD Winter, ECHAM5-A1B-scenario

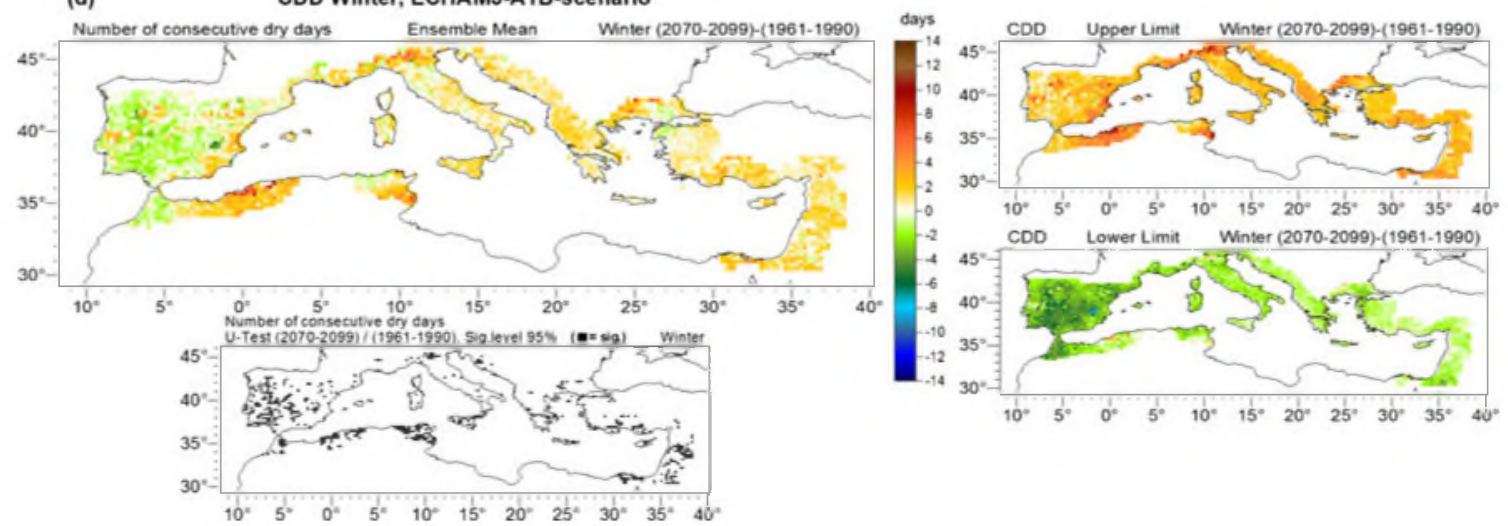


Fig. 5 Ensemble mean changes of the number of consecutive dry days for the future period 2070-2099 in relation to the control run period 1961-1990 under SRES A1B scenario assumptions. In addition the significance of the changes (black signature, significant at the $95 \%$ level, $U$ test) and the upper and lower limits of the $95 \%$ bootstrap confidence intervals are shown. Results are based on statistical downscaling assessments using generalized linear models as downscaling technique and predictors from three ECHAM5/MPI-OM runs. From top to bottom: spring, summer, autumn, winter

to the idea of a general broadening of the precipitation distribution in this area during winter.

\section{Discussion and conclusions}

In the present study, possible future changes of total precipitation, heavy rainfall events (expressed by indices based on the 95th percentile), and dry periods (represented by the maximum number of consecutive dry days) were assessed for the Mediterranean area until the end of the twenty-first century.

The projections were done by means of statistical downscaling applying GLMs as a particular downscaling technique. It could be shown that GLMs represent an appropriate method for the assessments, reflected in generally high values of the correlation coefficients between observation-based and statistically modeled time series and of other parameters describing model performances.

Within the scope of the statistical downscaling approach, geopotential heights of the 700 and $500 \mathrm{hPa}$ levels, zonal and meridional wind components of the $850 \mathrm{hPa}$ level, specific humidity of the 850 and $700 \mathrm{hPa}$ levels, as well as two convective indices (Showalter Index and convective inhibition) were selected as predictors to describe the

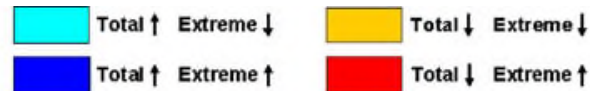

(a) Total precipitation versus extreme precipitation change

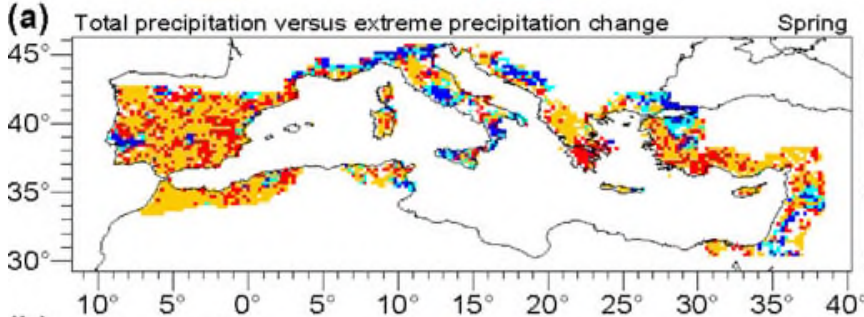

(b) Total precipitation versus extreme precipitation change Summer

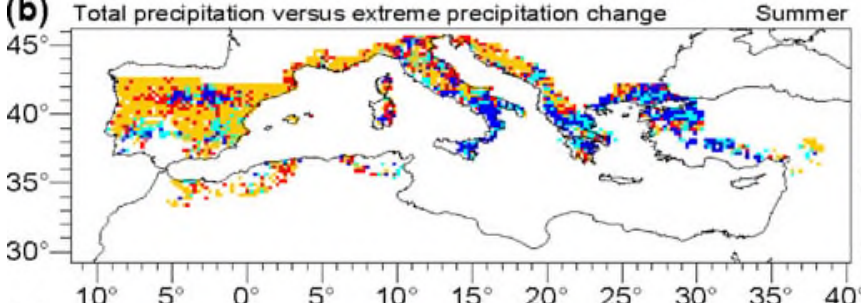

(c) Total precipitation versus extreme precipitation change Autumn

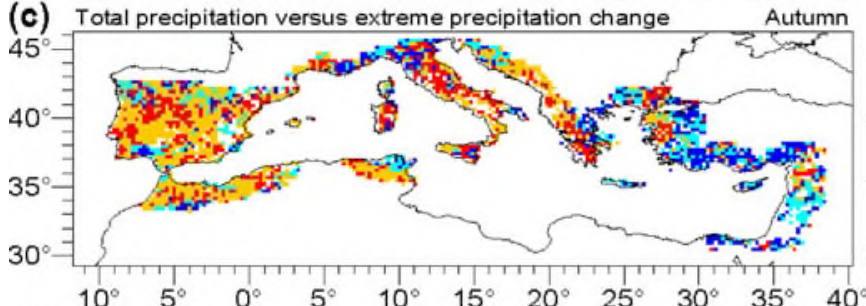

(d) Total precipitation versus extreme precipitation change

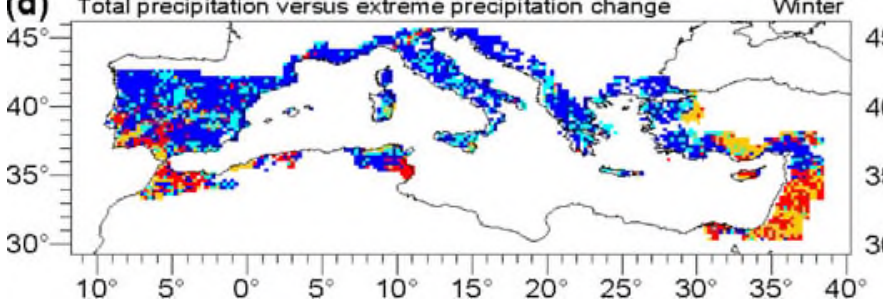

Fig. 6 Synopsis of the relationships of total and extreme precipitation changes (left side) and of total precipitation and dry periods changes (right side). Shown is in each case the sign of change between the
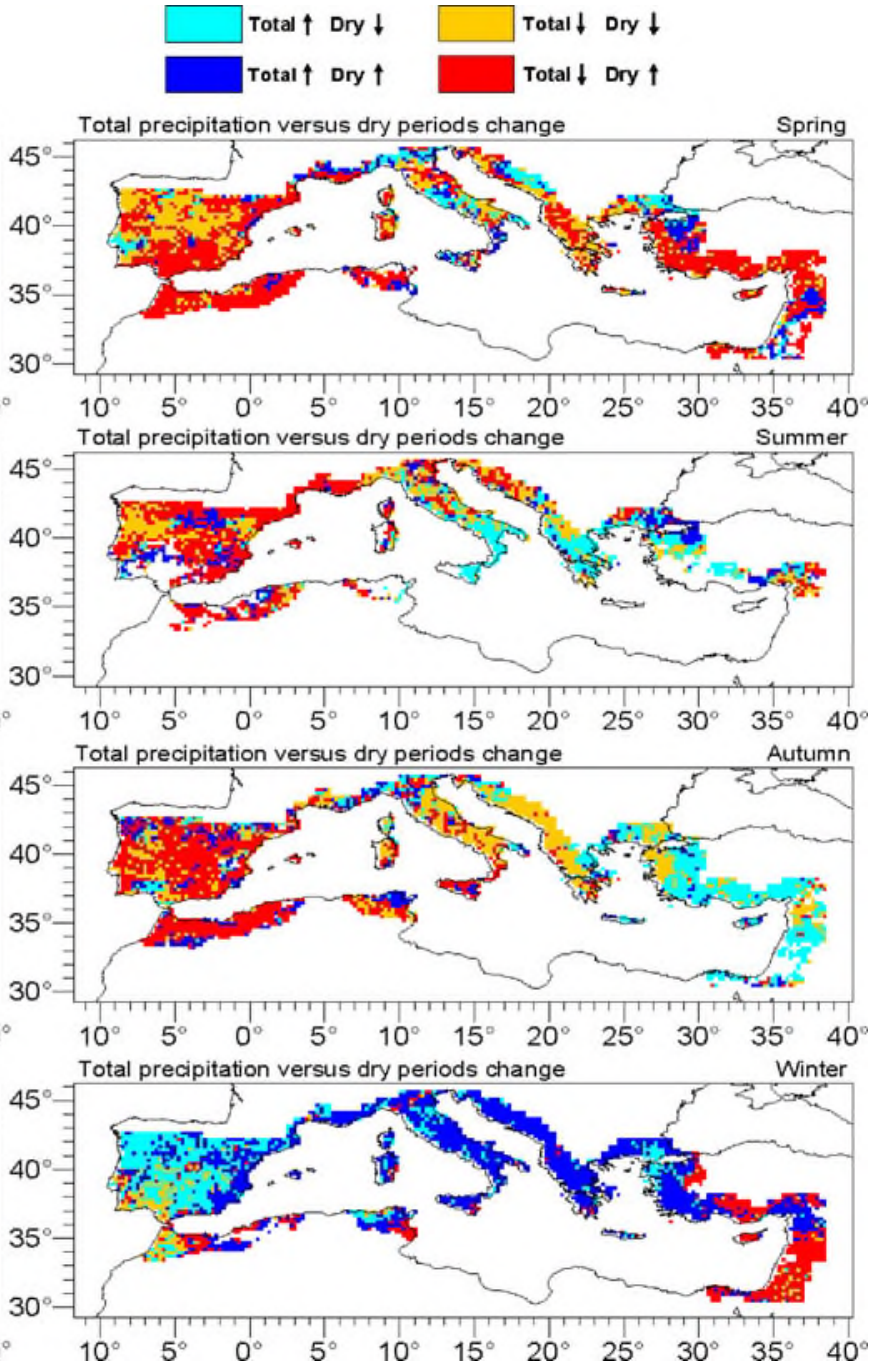

periods 2070-2099 and 1961-1990 of total and extreme precipitation, and of total precipitation and dry periods, respectively 
Table 4 Synopsis of the relationships of total and extreme precipitation and dry periods changes: number and percentage of grid boxes with a specific combination regarding the sign of change (+ increase, decrease) between the periods 2070-2099 and 1961-1990

\begin{tabular}{|c|c|c|c|c|}
\hline & & & Number of grid boxes & Percentage \\
\hline \multicolumn{5}{|l|}{ Spring } \\
\hline Mean + & Extreme + & Dry + & 147 & 5.82 \\
\hline Mean + & Extreme + & Dry - & 138 & 5.46 \\
\hline Mean + & Extreme - & Dry + & 148 & 5.86 \\
\hline Mean + & Extreme - & Dry - & 115 & 4.55 \\
\hline Mean - & Extreme + & Dry + & 460 & 18.21 \\
\hline Mean - & Extreme + & Dry - & 235 & 9.30 \\
\hline Mean - & Extreme - & Dry + & 899 & 35.59 \\
\hline Mean - & Extreme - & Dry - & 384 & 15.21 \\
\hline \multicolumn{5}{|l|}{ Summer } \\
\hline Mean + & Extreme + & Dry + & 129 & 7.00 \\
\hline Mean + & Extreme + & Dry - & 242 & 13.13 \\
\hline Mean + & Extreme - & Dry + & 132 & 7.16 \\
\hline Mean + & Extreme - & Dry - & 153 & 8.30 \\
\hline Mean - & Extreme + & Dry + & 188 & 10.20 \\
\hline Mean - & Extreme + & Dry - & 171 & 9.28 \\
\hline Mean - & Extreme - & Dry + & 547 & 29.68 \\
\hline Mean - & Extreme - & Dry - & 281 & 15.25 \\
\hline \multicolumn{5}{|l|}{ Autumn } \\
\hline Mean + & Extreme + & Dry + & 141 & 5.62 \\
\hline Mean + & Extreme + & Dry - & 337 & 13.43 \\
\hline Mean + & Extreme - & Dry + & 174 & 6.94 \\
\hline Mean + & Extreme - & Dry - & 266 & 10.60 \\
\hline Mean - & Extreme + & Dry + & 320 & 12.75 \\
\hline Mean - & Extreme + & Dry - & 299 & 11.92 \\
\hline Mean - & Extreme - & Dry + & 592 & 23.60 \\
\hline Mean - & Extreme - & Dry - & 380 & 15.14 \\
\hline \multicolumn{5}{|l|}{ Winter } \\
\hline Mean + & Extreme + & Dry + & 910 & 35.52 \\
\hline Mean + & Extreme + & Dry - & 484 & 18.89 \\
\hline Mean + & Extreme - & Dry + & 334 & 13.04 \\
\hline Mean + & Extreme - & Dry - & 169 & 6.60 \\
\hline Mean - & Extreme + & Dry + & 262 & 10.22 \\
\hline Mean - & Extreme + & Dry - & 98 & 3.83 \\
\hline Mean - & Extreme - & Dry + & 223 & 8.70 \\
\hline Mean - & Extreme - & Dry - & 82 & 3.20 \\
\hline
\end{tabular}

From top to bottom: spring, summer, autumn, winter

large-scale circulation and thermodynamic conditions. Overall, it became apparent that $700 \mathrm{hPa}$ geopotential heights constitute the most prominent predictor for all assessed predictands, indicating that the large-scale lowertropospheric circulation is of primary importance for precipitation-related events in the Mediterranean area. In addition, specific predictor configurations occurred depending on the target variable and the season being analyzed. For example, for all predictands considered in this paper, meridional wind components were of great relevance in spring and autumn being those seasons when meridional circulation patterns have their maximum impact on the Mediterranean area. For total precipitation and dry periods, convective inhibition played an important role in spring and summer (for the latter also in autumn), hinting to the requirement of sufficiently small convective inhibition to initiate convective rainfall formation. In contrast, specific humidity represented an important predictor particularly for extreme precipitation and for dry periods in all seasons, being of relatively little relevance, however, for total precipitation in spring and autumn. In the latter case, the largescale atmospheric setting, expressed by geopotential heights and wind components, was more important than thermodynamic forcing for rainfall formation.

A specific statistical ensemble technique which comprises up to five statistical ensemble members per grid box has been used for the assessments. This led to a range of possible future realizations of precipitation depending on the specific predictors-predictand relationships identified in the individual calibration periods. Furthermore, two different scenarios (A1B and B1 scenario), multiple runs for each scenario, and output of two different AOGCMs (ECHAM5 and $\mathrm{HadCM} 3$ ) have been applied in the present study. Thus, the results presented in Figs. 2, 3, 5, and 6 are ensemble means based on the different statistical ensemble members applied to the three ECHAM5-A1B-runs. Looking at the individual realizations making up the ensemble means it becomes evident that the spread of the results is greater among the statistical ensemble members compared to the variation arising from the application of different GCM runs. This is a sign of the presence of nonstationarities in the predictors-predictand relationships, forming a major source of uncertainty within statistical downscaling assessments. In order to account for this, statistical ensembles have been built in the present study. However, future work is necessary to explicitly deal with nonstationarities in the context of statistical downscaling.

\subsection{Total precipitation}

Regarding the changes of total precipitation until the end of the twenty-first century, main decreases were assessed over the Mediterranean area in spring. In summer and autumn, the western and central-northern Mediterranean regions are going to be predominantly affected by precipitation decreases, whereas the eastern Mediterranean area might see rather increases. In winter, widespread increases were projected with the exception of the eastern Mediterranean area being dominated by decreases. For winter and spring, the described statistical downscaling results are largely 
consistent with the results obtained in a previous study by Hertig and Jacobeit (2008) using ECHAM4/OPYC3 predictors $(1,000 / 500 \mathrm{hPa}$ geopotential heights and $1,000 \mathrm{hPa}$ specific humidity) under SRES B2-scenario assumptions. In autumn, some differences become apparent, mainly related to the north-eastern and eastern Mediterranean area with mostly increases assessed in the present study and decreases in the former assessment. The reasons for these distinctions may be related to differences in the spatial and temporal resolutions of the predictand, differences in the set of predictor variables, differing downscaling techniques, different emission scenarios, and the application of different GCM generations.

In conclusion, although total precipitation mainly increases in winter, it decreases during other seasons, leading to a total decrease of $0.065 \mathrm{~mm} /$ day in the annual mean as quantified by Gibelin and Déqué (2003). According to the IPCC AR4 (Meehl et al. 2007), total annual precipitation shows widespread decreases around the subtropical zones. These decreases are attributed to the widening of the descending branches of the Hadley circulation ( $\mathrm{Lu}$ and Vecchi 2007) and to increases of the atmospheric stability on the margins of the tropical convection zones (Neelin et al. 2006). However, regional modifications from this general pattern of change are possible as seen in the statistical downscaling projections of the present study and in RCM projections, too (e.g., Gao et al. 2006). For example, such modifications concern regional increases of total precipitation in summer and autumn which are caused by changing thermodynamic conditions as well as by circulation changes. These aspects have to be analyzed in more detail by forthcoming investigations, since direct GCM output does not give any indication of precipitation increases in these seasons (Giorgi and Lionello 2008). Possible reasons for these disagreements might be related to the coarse GCM grid resolution resulting in an insufficient representation of precipitation events influenced by small-scale orographic features resulting in dry bias over mountains (Giorgi and Coppola 2009). On the other hand, statistical downscaling might suffer from the missing incorporation of predictors describing important boundary conditions like soil moisture and SST as suggested by Palatella et al. (2010). Thus, Rowell and Jones (2006) point out that dry summers in the Mediterranean area are mainly due to reduced soil moisture conditions in spring leading to reduced summer convection, and that the large land-sea contrast in warming leads to reduced relative humidity and precipitation over the continent

\subsection{Extreme precipitation}

On a seasonal basis, extreme precipitation amount and its relation to total precipitation were expressed by the indices
R95AM (precipitation total from events exceeding the 95th percentile) and $\mathrm{R} 95 \mathrm{~T}$ (percentage of total precipitation from events exceeding the 95 th percentile). The statistical downscaling results for R95AM yielded widespread decreases in spring until the end of the twenty-first century. But since total precipitation is projected to decrease as well, R95T is only slightly reduced or even shows small increases. In summer, reductions of R95AM were assessed over the western and northern Mediterranean area and increases around the Tyrrhenian Sea, the Ionian Sea, and the Aegean Sea. The spatial pattern of R95AM and total precipitation changes shows large similarities again, but in terms of absolute amounts the changes are not uniform, reflected in the (partially considerable) changes of R95T. In autumn, increases of R95AM, R95T, and of total precipitation can mainly be found over the northern coast of the Ligurian Sea, Greece, and the southern coast of Turkey. Regarding changes in 1-day precipitation extremes, several RCMs also exhibit increases in autumn over the Mediterranean Sea and Italy (Frei et al. 2006). Decreases of R95AM dominate in almost any other Mediterranean region in this season. With the exception of the central Iberian Peninsula, the decreases of R95AM are accompanied by decreases of R95T, because extreme precipitation is stronger reduced than total precipitation. In contrast, over the central Iberian Peninsula the decline of total precipitation is stronger than R95AM reductions, causing R95T to increase. In winter, proportional increases of R95AM and total precipitation dominate over the Mediterranean area, resulting in only small changes of R95T. Based on regional climate modeling, Nikulin et al. (2011) also simulate a significant increase of wintertime precipitation extremes in Italy and parts of the Iberian and Balkan Peninsulas. Oikonomou et al. (2008) assess increases of winter precipitation intensity around the Aegean Sea, Crete, Cyprus, and Turkey. In contrast, Frei et al. (2006) project for winter that the Mediterranean region experiences only small changes in precipitation extremes with a general tendency towards decreases.

In summary, a very complex pattern of extreme precipitation changes in the Mediterranean area arises from various downscaling results. The general pattern of change derived from direct AOGCM output with increases over the northern Mediterranean regions and decreases in the southern and eastern parts (e.g., Tebaldi et al. 2006) is partly, but substantially modified in dynamical and statistical downscaling results. This can be related to the fact that heavy precipitation events in the Mediterranean area are controlled by many small-scale factors like topographic details, local moisture availability, and regional peculiarities of atmospheric circulation patterns. Moreover, the diversity of the regional information arising from different downscaling assessments indicates the large uncertainties inherent in the regional projections of future climate change and points to the 
necessity of additional investigations to reduce these uncertainties, especially within the context of extremes.

\subsection{Dry periods}

Concerning the changes of dry periods as expressed by the maximum number of consecutive dry days (CDD) per season, mainly a prolongation until the end of the twenty-first century is assessed in spring over the southern and eastern parts of the Mediterranean area. In contrast, the northern Mediterranean regions show decreases of CDD in spring. In summer, strong and significant modifications of CDD become visible widespread over the Mediterranean area with extensions of CDD over the southeastern parts of the Iberian Peninsula and the western parts of Mediterranean North Africa, but shortenings of CDD over the Ionian Sea and the Aegean Sea. In autumn, the overall pattern of change is characterized by a prolongation of CDD over the western Mediterranean area and a shortening of CDD over the eastern Mediterranean area. In the winter season, small and mostly nonsignificant increases of CDD are assessed over the whole Mediterranean area with the exception of the western parts where some decreases are indicated.

According to a study of Dai (2011) using the IPCC twentieth century and SRES A1B simulations, it is a striking feature that aridity increases since the late twentieth century and will become severe drought by the 2060s over the Mediterranean area with precipitation decreases being largely responsible for the drying (in contrast to other midlatitude and subtropical regions like, e.g., southeast Asia where increased evaporation is a major cause for the increased aridity). Gibelin and Déqué (2003) note that (besides the anticipated precipitation changes) evaporation increases in winter and spring, but decreases in summer and fall, despite the higher surface temperature. This evolution suggests that evaporation will be limited by a decrease in soil wetness during the latter two seasons. In the present study, the relationship of decreasing total precipitation and prolonging dry periods holds in spring for many regions across the Mediterranean area (e.g., southern Spain, western North Africa, Mediterranean Turkey), in summer and autumn primarily for the western Mediterranean area, and in winter for the eastern Mediterranean area. Beyond that, total precipitation and dry periods are projected to follow different modes of change in the Mediterranean area until the end of the twenty-first century. In conjunction with extreme precipitation changes, this topic is taken on to the following last section.

\subsection{Synopsis}

From the previous sections and especially from Section 3.4 and Fig. 6, it became apparent that all combinations of change in total precipitation, extreme precipitation, and dry periods might occur in the Mediterranean area under conditions of future climate change, but some distinct features can be highlighted: first of all there is generally a different evolution of precipitation-related events over the western and central-northern Mediterranean regions compared to the eastern Mediterranean area. This feature has been described for observational periods in several studies (e.g., Duenkeloh and Jacobeit 2003; Maheras et al. 1999) and is seen in the context of the so-called "Mediterranean Oscillation" (Conte et al. 1989), a regional dynamical system with prevailingly opposite pressure patterns over the western and eastern Mediterranean area. In the present study, the changes of precipitation-related events until the end of the twenty-first century have been assessed by using predictors describing the large-scale circulation as well as by the application of predictors specifying thermodynamic conditions. As a result, total and extreme precipitation over the western and central-northern Mediterranean area are mostly reduced in summer and autumn, but show increases in winter. In contrast, precipitation over the eastern Mediterranean area shows widespread increases in summer and autumn, but declines in winter. Note however that the described general tendencies have a spatially varying extent during different seasons. In spring, the opposite behavior between the western and eastern Mediterranean regions is not apparent at all; in this season, total and extreme precipitation decreases dominate over the whole Mediterranean area and are often accompanied by a prolongation of the maximum number of consecutive dry days. This connection also exists in the other seasons. Vice versa, precipitation increases are commonly accompanied by dry period decreases with the exception of large parts around the central-northern Mediterranean area in winter indicating increases of both precipitation and dry period length.

Altogether, the above highlighted main changes can be integrated into the view of a general shift of the whole precipitation distribution towards higher and lower values, respectively. Beyond that, it is interesting that areas with mean precipitation being reduced and extreme precipitation being increased are not that common. Thus, this feature which is suggested by some AOGCMs as the typical mode of change in the subtropics (Meehl et al. 2007; Kharin and Zwiers 2005), might not be dominant in the Mediterranean area.

Changes of total versus extreme precipitation and dry periods in the Mediterranean area until the end of the twenty-first century have been addressed in the present study by means of statistical downscaling of seasonal precipitation totals and particular precipitation-related indices. To further explore questions concerning mean and extreme precipitation changes, distribution-based approaches are particularly promising as for example that one by Vrac and Naveau (2007) who applied a probability mixture model of gamma and generalized Pareto distributions within a stochastic weather typing 
approach to improve the downscaling of local precipitation. This field of research will be part of future investigations to enhance the quality and consistency of regional to local climate change information for the Mediterranean area.

Acknowledgments Financial support is provided by the DFG (German Research Foundation). We acknowledge the E-OBS dataset from the EU-FP6 project ENSEMBLES (http://ensembles-eu-metoffice. com) and the data providers in the ECA\&D project (http://eca.knmi.nl).

\section{Appendix 1}

Calculation of convective indices

The Showalter Index (Showalter 1953) is used to describe convective instability and is calculated as follows:

Showalter - Index $=T_{500}-\mathrm{TLCL}_{500}$

$T_{500}$ : temperature at the $500 \mathrm{hPa}$ level

$\mathrm{TLCL}_{500}$ : temperature that an air parcel will achieve if it is lifted dry adiabatically from the $850 \mathrm{hPa}$ level to its condensation level and then moist adiabatically to the $500 \mathrm{hPa}$ level.

The difference between the $500 \mathrm{hPa}$ temperature and the lifted air parcel temperature provides an estimate of the instability. It should be noted that the Showalter Index does not take into account the atmospheric conditions below the $850 \mathrm{hPa}$ level. To calculate the Showalter Index from the reanalysis data and the GCM data, $850 \mathrm{hPa}$ air temperature and $850 \mathrm{hPa}$ relative humidity are used to calculate the dew point temperature, and from this the height of the condensation level at each grid box. The difference of the geopotential heights of the 500 and $850 \mathrm{hPa}$ levels is used to obtain the absolute height of the air parcel lifting. The value of the moist adiabatic temperature gradient above the condensation level is readjusted in steps of $100 \mathrm{~m}$ uplift.

$\mathrm{CIN}$, characterizing the presence of large- or small-scale lifting mechanisms, is represented by a proxy, following Myoung and Nielsen-Gammon (2010):

$\mathrm{CIN}=T(\mathrm{inv})-T_{d}(s)$

$T_{d}(s)$ : dewpoint temperature at the surface

$T$ (inv): virtual temperature at some level just above the mixed layer or within a capping.

According to Myoung and Nielsen-Gammon (2010), surface pressure values can be taken to obtain the associated best proxy levels for the calculation of the proxy of CIN. In the present study, the assumed best proxy level for each grid box of the predictor domain is determined by taking Table 1 in Myoung and Nielsen-Gammon (2010). Thus, for the calculation of CIN from the reanalysis data and the GCM output, surface dewpoint temperatures are required as well as surface pressure data (to obtain the best proxy level), and additionally specific humidity and air temperature of the best proxy level (for the calculation of the virtual temperature).

\section{References}

Ben-Gai T, Bitan A, Manes A, Alpert P, Rubin S (1998) Spatial and temporal changes in rainfall frequency distribution patterns in Israel. Theor Appl Climatol 61:177-190

Beniston M, Stephenson D, Christensen O, Ferro C, Frei C, Goyette S, Halsnaes K, Holt T, Jylhä K, Koffi B, Palutikof J, Schöll R, Semmler T, Woth K (2007) Future extreme events in European climate: an exploration of regional climate model projections. Clim Chang 81:71-95

Brunetti M, Maugeri M, Nanni T (2001) Changes in total precipitation, rainy days and extreme events in northeastern Italy. Int J Climatol 21:861-871

Brunetti M, Maugeri M, Monti F, Nanni T (2004) Changes in daily precipitation frequency and distribution in Italy over the last 120 years. J Geophys Res 109:D05102. doi:10.1029/2003JD004296

Conte M, Giuffrida S, Tedesco S (1989) The Mediterranean oscillation: impact on precipitation and hydrology in Italy. Proceedings of the Conference on Climate and Water, vol. 1. Publications of Academy of Finland, Helsinki, pp 121-137

Dai A (2011) Drought under global warming: a review. Wiley Interdiscip Rev Clim Chang 2:45-65. doi:10.1002/wcc.81

DiCiccio TJ, Efron B (1996) Bootstrap confidence intervals. Stat Sci 11:189-228

Duenkeloh A, Jacobeit J (2003) Circulation dynamics of Mediterranean precipitation variability 1948-1998. Int J Climatol 23:18431866

Emori S, Brown SJ (2005) Dynamic and thermodynamic changes in mean and extreme precipitation under changed climate. Geophys Res Lett 32:L17706

Frei C, Schöll R, Fukutome S, Schmidli J, Vidale PL (2006) Future change of precipitation extremes in Europe: intercomparison of scenarios from regional climate models. J Geophys Res 111: D06105. doi:10.1029/2005JD005965

Gao X, Pal JS, Giorgi F (2006) Projected changes in mean and extreme precipitation over the Mediterranean region from high resolution double nested RCM simulations. Geophys Res Lett 33:L03706

Gibelin AL, Déqué M (2003) Anthropogenic climate change over the Mediterranean region simulated by a global variable resolution model. Clim Dyn 20:327-339

Giorgi F (2006) Climate change hotspots. Geophys Res Lett 33: L08707. doi:10.1029/2006GL025734

Giorgi F, Coppola E (2009) Projections of 21st century climate over Europe. Eur Phys J 1:29-46, Web of Conferences

Giorgi F, Lionello P (2008) Climate change projections for the Mediterranean area. Glob Planet Chang 63:90-104

Gordon C, Cooper C, Senior CA, Banks HT, Gregory JM, Johns TC, Mitchell JFB, Wood RA (2000) The simulation of SST, sea ice extents and ocean heat transports in a version of the Hadley Centre coupled model without flux adjustments. Clim Dyn 16:147-168

Haylock MR, Hofstra N, Klein Tank AMG, Klok EJ, Jones PD, New M (2008) A European daily high-resolution gridded dataset of surface temperature and precipitation. J Geophys Res-Atmos 113: D20119. doi:10.1029/2008JD10201

Hertig E, Jacobeit J (2008) Assessments of Mediterranean precipitation changes for the 21 st century using statistical downscaling techniques. Int J Climatol 28:1025-1045 
Hertig E, Seubert S, Paxian A, Vogt G, Paeth H, Jacobeit J (2011) Statistical modeling of extreme precipitation for the Mediterranean area under future climate change. Int J Climatol

Hertig E, Paxian A, Vogt G, Seubert S, Paeth H, Jacobeit J (2012) Statistical and dynamical downscaling assessments of precipitation extremes in the Mediterranean area. Meteorol Z 21:61-77

Jansa A, Genoves A, Picornell MA, Campins J, Riosalido R, Carretero O (2001) Western Mediterranean cyclones and heavy rain. Part 2: statistical approach. Meteorol Appl 8:43-56

Kalnay E, Kanamitsu M, Kistler R, Collins W, Deaven D, Gandin L, Iredell $\mathrm{M}$, Saha $\mathrm{S}$, White $\mathrm{G}$, Woollen J, Zhu Y, Chelliah $\mathrm{M}$, Ebisuzaki W, Higgins W, Janowiak J, Mo KC, Ropelewski C, Wang J, Leetmaa A, Reynolds R, Jenne R, Joseph D (1996) The NCEP/NCAR 40-year reanalysis project. Bull Am Meteorol Soc 77:437-471

Kharin V, Zwiers F (2005) Estimating extremes in transient climate change simulations. J Clim 18:1156-1173

Kistler R, Kalnay E, Collins W, Saha S, White G, Woollen J, Chelliah M, Ebisuzaki W, Kanamitsu M, Kousky V, van den Dool H, Jenne R, Fiorino M (2001) The NCEP/NCAR 50-year reanalysis: monthly means CD-ROM and documentation. Bull Am Meteorol Soc 82:247-268

Lana X, Burgueño A (1997) Probabilities of repeated long dry episodes based on the Poisson distribution. An example for Catalonia (NE Spain). Theor Appl Climatol 60:111-120

Lana X, Burgueño A (2000) Some statistical characteristics of monthly and annual pluviometric irregularity of the Spanish Mediterranean coast. Theor Appl Climatol 65:79-97

Lionello P, Giorgi F (2007) Winter precipitation and cyclones in the Mediterranean region: future climate scenarios in a regional simulation. Adv Geosci 12:153-158

Lu J, Vecchi GA, Reichler T (2007) Expansion of the Hadley cell under global warming. Geophys Res Lett 34:L06805. doi:06810.01029/ 02006GL028443

Maheras P, Xoplaki E, Kutiel H (1999) Wet and dry monthly anomalies across the Mediterranean basin and their relationship with circulation, 1860-1990. Theor Appl Climatol 64:189-199

Mann HB, Whitney DR (1947) On a test whether one of two random variables is stochastically larger than the other. Ann Math Stat 18:50-60

McCullagh P, Nelder JA (1989) Generalized linear models. Monographs on statistics and applied probability 37. Chapman \& Hall, London

Meehl GA, Arblaster JM, Tebaldi C (2005) Understanding future patterns of precipitation extremes in climate model simulations. Geophys Res Lett 32:L18719. doi:10.1029/2005GL023680

Meehl GA, Stocker TF, Collins WD, Friedlingstein P, Gaye AT, Gregory JM, Kitoh A, Knutti R, Murphy JM, Noda A, Raper SCB, Watterson IG, Weaver AJ, Zhao Z-C (2007) Global Climate Projections. In: Solomon S, Qin D, Manning M, Chen Z, Marquis M, Averyt KB, Tignor M, Miller HL (eds) Climate Change 2007: The Physical Science Basis. Contribution of Working Group I to the Fourth Assessment Report of the Intergovernmental Panel on Climate Change. Cambridge University Press, Cambridge, United Kingdom and New York, NY, USA

Moberg A, Jones PD, Lister D, Walther A, Brunet M, Jacobeit J, Alexander LV, Della-Marta P, Luterbacher J, Yiou P, Chen D, Klein Tank A, Saladié O, Sigró J, Aguilar E, Alexandersson H, Almarza C, Auer I, Barriendos M, Begert M, Bergström H, Böhm R, Butler CJ, Caesar J, Drebs A, Founda D, Gerstengarbe F-W, Micela G, Maugeri M, Österle H, Pandzic K, Petrakis M, Srnec L, Tolasz R, Tuomenvirta H, Werner PC, Linderholm H, Philipp A,
Wanner H, Xoplaki E (2006) Indices for daily temperature and precipitation extremes in Europe analysed for the period 19012000. J Geophys Res-Atmos 111:D22106. doi:10.1029/ 2006JD007103

Myoung B, Nielsen-Gammon JW (2010) Sensitivity of monthly convective precipitation to environmental conditions. J Clim 23:166-188

Nakicenovic N, Swart R. (eds) (2000) Emissions scenarios 2000. Special Report of the Intergovernmental Panel on Climate Change, Cambridge University Press, Cambridge, pp 570

Neelin JD, Münnich M, Su H, Meyerson JE, Holloway CE (2006) Tropical drying trends in global warming models and observations. Proc Natl Acad Sci 103:6110-6115

Nikulin G, Kjellström E, Hansson U, Strandberg G, Ullerstig A (2011) Evaluation and future projections of temperature, precipitation and wind extremes over Europe in an ensemble of regional climate simulations. Tellus $63 \mathrm{~A}: 41-55$

Oikonomou Ch, Flocas HA, Hatzaki M, Asimakopoulos DN, Giannakopoulos C (2008) Future changes in the occurrence of extreme precipitation events in eastern Mediterranean. Glob NEST J 10(2):255-262

Palatella L, Miglietta MM, Paradisi P, Lionello P (2010) Climate change assessment for Mediterranean agricultural areas by statistical downscaling. Nat Hazards Earth Syst Sci 10:1647-1661

Philipp A, Della-Marta PM, Jacobeit J, Fereday DR, Jones PD, Moberg A, Wanner H (2007) Long term variability of daily North AtlanticEuropean pressure patterns since 1850 classified by simulated annealing clustering. J Clim 20(16):4065-4095

Pope V, Gallani ML, Rowntree PR, Stratton RA (2000) The impact of new physical parameterizations in the Hadley Centre climate model: HadAM3. Clim Dyn 16:123-146

Preisendorfer RW (1988) Principal component analysis in meteorology and oceanography. In: CD Mobly (ed.). Developments in atmospheric sciences, 17, 425 pp

Roeckner E, Baeuml G, Bonaventura L, Brokopf R, Esch M, Giorgetta M, Hagemann S, Kirchner I, Kornblueh L, Manzani E, Rhodin A, Schlese U, Schulzweida U, Tompkins A (2003) The atmospheric general circulation model ECHAM5. Part I: Model description. Max Planck Institute for Meteorology Report 349, Hamburg

Roeckner E, Brasseur GP, Giorgetta M, Jacob D, Jungclaus J, Reick C, Sillmann J (2006) Climate projections for the 21st century. Max Planck Institute for Meteorology, Hamburg

Rowell DP, Jones RG (2006) Causes and uncertainty of future summer drying over Europe. Clim Dyn 27:281-299

Showalter AK (1953) A convective index as an indicator of cumulonimbus development. J Appl Meteorol 5:839-846

Sillmann J, Roeckner E (2008) Indices of extreme events in projections of anthropogenic climate change. Clim Chang 86:83-104

Tebaldi C, Hayhoe K, Arblaster J, Meehl G (2006) Going to the extremes: an intercomparison of model-simulated historical and future changes in extreme events. Clim Chang 79:185-211

Vrac M, Naveau P (2007) Stochastic downscaling of precipitation: from dry events to heavy rainfalls. Water Resour Res 43:W07402

Wang G (2005) Agricultural drought in a future climate: results from 15 global climate models participating in the IPCC 4th Assessment. Clim Dyn 25:739-753

Weiß M, Flörke M, Menzel L, Alcamo J (2007) Model-based scenarios of Mediterranean droughts. Adv Geosci 12:145-151

Wilby RL, Wigley TML (2000) Precipitation predictors for downscaling: observed and general circulation model relationships. Int J Climatol $20: 641-661$ 